\title{
Characteristics of storm time ion composition in the near-Earth plasma sheet using Geotail and RBSP measurements
}

\author{
Megha Pandya', Bhaskara Veenadhari ${ }^{*}$ (D, Masahito Nosé ${ }^{2}$, Sandeep Kumar', Geoff D. Reeves ${ }^{3}$ and A. T. Y. Lui ${ }^{4}$
}

\begin{abstract}
Solar wind particles and ionospheric $\mathrm{O}^{+}$ions influence the near-Earth plasma sheet and inner magnetospheric composition. We studied the behavior of $\mathrm{H}^{+}, \mathrm{O}^{+}$and $\mathrm{He}^{+}$ions (9-210 keV) for intense and moderate geomagnetic storms of solar cycle 23 and 24. An average energy density $\langle\varepsilon>$ of ions over a given interval and flux enhancement is estimated using observations from satellites at different $L$ values, namely STICS sensor on-board Geotail spacecraft and HOPE spectrometer on-board Radiation Belt Storm Probes. It provides a comprehensive understanding of the energy density variation of $\mathrm{H}^{+}, \mathrm{O}^{+}$and $\mathrm{He}^{+}$ions with the strength of IMF Bz, Psw, intensity of storms and $L$ value. Statistically, we observed that (1) In the plasma sheet region, during main phase of the intense geomagnetic storm, $\left\langle\varepsilon_{\mathrm{O}+/ H_{+}}\right\rangle$ and $\left\langle\varepsilon_{\mathrm{He}+/ \mathrm{H}+}>\right.$ enhances, $(2)<\varepsilon_{\mathrm{O}+/ \mathrm{H}+}>$ is well correlated with PsW $(C C=0.86)$ and IMF Bz $(C C=0.85),(3)<\varepsilon_{\mathrm{O}_{+} / \mathrm{H+}}>$ shows higher correlation $(C \mathrm{CC}=0.73)$ with $\mathrm{Kp}$ than $\left\langle\varepsilon_{\mathrm{He}+/ \mathrm{H}_{+}}>(\mathrm{CC}=0.65)\right.$, indicating a fairly good dependence on the strength of geomagnetic activity, $(4)<\varepsilon_{\mathrm{O}+/ \mathrm{H}+}>$ and $\left\langle\varepsilon_{\mathrm{He}+/ \mathrm{H}_{+}}>\right.$dependence on $\mathrm{L}$ value indicates that $\mathrm{O}^{+} / \mathrm{H}^{+}$ and $\mathrm{He}^{+} / \mathrm{H}^{+}$is more pronounced near $L=3$. It is a cumulative extension of the previous studies on ion composition change which is in accordance with the existing picture of the plasma sheet and inner magnetosphere.
\end{abstract}

Keywords: Inner magnetosphere, Plasma sheet, Ion composition, Energy density, Geomagnetic storm

\section{Introduction}

The Earth's magnetosphere is formed by the deflection of continuously flowing solar wind and the geomagnetic field. The motion of the charged particles (coming from the solar wind) in the Earth's magnetosphere is governed by the existing electric and magnetic fields. A charged particle gets trapped in the different regions of the Earth's inner magnetosphere depending upon its energies and the strength of convection electric field. During a geomagnetic storm, the ring current ion composition changes considerably (Daglis et al. 1999). Gloeckler et al. (1985) found that the quiet time ring current consists of mainly protons $\left(\mathrm{H}^{+}\right)$, while the intense storm time ring current is dominated by $\mathrm{O}^{+}$ions. The numerical simulations have shown that at the time of solar maxima,

\footnotetext{
*Correspondence: veenaiig@gmail.com; bveena@iigs.iigm.res.in

${ }^{1}$ Indian Institute of Geomagnetism, New Panvel, Navi Mumbai - 410218, India

Full list of author information is available at the end of the article
}

geomagnetic main phase ring current is dominated by the energy density of $\mathrm{O}^{+}$ions (Jordanova et al. 2001; Kozyra et al. 2002).

The near-Earth plasma sheet contains a mixture of ions, both from the ionosphere $\left(\mathrm{O}^{+}, \mathrm{He}^{+}\right.$and $\left.\mathrm{N}^{+}\right)$and solar wind $\left(\mathrm{H}^{+}, \mathrm{H}^{++}\right.$and $\left.\mathrm{He}^{+}\right)$(Daglis 2006) which is the direct source of ring current (Jordanova 2013). The ultimate source of main phase ring current is the inward convection of plasma from the nightside plasma sheet region (Keika et al. 2013). André (2015) developed a new technique to detect low-energy $(\mathrm{eV})$ ionospheric ions by detecting the wake behind a charged spacecraft in a supersonic ion flow. Ionospheric ions are a major source of the magnetospheric plasma during a geomagnetic storm and quiet conditions (Chappell et al. 1987). The characteristics of ionospheric heavy ions (like $\mathrm{O}^{+}$) in the magnetosphere has been extensively studied by many researchers (Pulkkinen et al. 2001; Greenspan and Hamilton 2002; Nosé et al. 2005; Ebihara et al. 2006; Yu and Ridley 2013; Kronberg et al. 2014). In the near-Earth 
plasma sheet region, during geomagnetic storm main phase, an extensive enhancement in $\mathrm{O}^{+}$ion energy density is observed compared to $\mathrm{H}^{+}$ions (Nosé et al. 2001). Nosé et al. (2005) studied the dynamics of the ionospheric ions using Geotail/EPIC instrument and IMAGE/ LENA satellite for the superstorm of 29-31 October 2003. They found that the energy density ratio for $\mathrm{O}^{+} /$ $\mathrm{H}^{+}$reached $10-20$ during the storm maxima. This was the largest ratio observed by Geotail in the near-Earth plasma sheet, giving more than $90 \%$ of $\mathrm{O}^{+}$ions out of the total energy density observed. Zhao et al. (2015) studied the evolution of ring current ion energy density for 29 March 2013 geomagnetic storm (Dst $=-61 \mathrm{nT}$ ), using Radiation Belt Storm Probes (RBSP). During the main phase of this geomagnetic storm, $\mathrm{O}^{+}$ions contributed $\sim 25 \%$ of the ring current energy content of which maximum contribution is from $<50 \mathrm{keV}$ energy range. This indicates an important role of ionosphere to the ring current ions even during moderate geomagnetic storms. Recently, using Cluster mission, Kronberg et al. (2017) extensively studied that the contribution of $>40 \mathrm{keV}$ heavy ions to the plasma sheet pressure becomes significant as the geomagnetic storm main and recovery phase is approached. However, during the geomagnetically quiet phase, $<40 \mathrm{keV}$ ions play a negligible role in the ring current pressure.

Numerous studies on the acceleration mechanism of the charged particles trapped in the magnetosphere have been proposed. Of these, magnetic field dipolarization is a very peculiar phenomena which is capable of accelerating ions to few hundreds of $\mathrm{keV}$ (Takahashi et al. 1987). During geomagnetic storms, the substorm phenomenon is very prominent which collectively gives the ion composition change. At substorm onsets, $\mathrm{O}^{+}$ions are more effectively accelerated than $\mathrm{H}^{+}$ions in the near-Earth plasma sheet (Möbius et al. 1987). Ohtani et al. (2015) explained the velocity filtering effect for $\mathrm{O}^{+}$ion energization which is much more effective closer to the neutral sheet, wherein the plasma flows perpendicular to the local magnetic field. Grigorenko et al. (2015) studied the energy spectra for $\mathrm{H}^{+}, \mathrm{He}^{+}$and $\mathrm{O}^{+}$ions using Cluster/ RAPID instrument. They found that the heavy ions were more effectively accelerated by ion resonant interactions with low-frequency electromagnetic fluctuation in the plasmoids associated with turbulence. A thorough review of the acceleration mechanism of $\mathrm{O}^{+}$ions is discussed by Nosé et al. (2016) and Kistler et al. (2016). The plausible mechanism responsible for ion acceleration has been addressed in the discussion part.

Earlier works are confined to the importance of ionospheric ions and its dependence on the severity of the geomagnetic storm. They addressed the role of ionosphere as a source of plasma sheet ions upon analyzing a couple of events using the satellite-based observations, whereas the importance of IMF $\mathrm{Bz}$ and solar wind dynamic pressure in the near-Earth plasma sheet has been studied by many researchers like Kronberg et al. (2012, 2015) but not specifically pertaining to the magnetic storms and it will be given in the present work. A cumulative study of intense and moderate geomagnetic storms of solar cycle 23 and 24 is studied by relating energy density and flux enhancement for $\mathrm{O}^{+}, \mathrm{H}^{+}$and $\mathrm{He}^{+}$ions. Two spacecraft observations cover the different regions in the near-Earth plasma sheet that explains the dynamics of the ion composition in space and time domain along with the energy density estimation in different $L$ values. "Data" section of the present study deals with the data collected from different satellites like Advanced Composition Explorer (ACE), Wind, Geotail and RBSP along with the selection of geomagnetic storm events. "Analysis and results: Geotail and RBSP observations" section discusses the statistical analysis and their comparison. "Discussion" section is the discussion followed by conclusions in "Summary" section.

\section{Data}

In the present work, we compiled a list of moderate and intense geomagnetic storms that occurred during solar cycle 23 and 24 using Dst index from World Data Centre for Geomagnetism, Kyoto. One-minute resolution Sym-H and hourly Dst index, both are almost alike (Sugiura et al. 1964) giving a measure of magnetic storm activity; the only difference is the time resolution and the set of the stations taken into consideration (Iyemori et al. 2010). The Kp index data are obtained from GFZ German Research Centre for Geosciences. Sym- $\mathrm{H}$ and the interplanetary data like interplanetary magnetic field (IMF) $\mathrm{Bz}$ and solar wind dynamic pressure were observed at $1 \mathrm{AU}$ from ACE spacecraft. The selected geomagnetic storm events are categorized into moderate $(-100 \mathrm{nT}<$ Sym- $\mathrm{H}<-50 \mathrm{nT})$ and intense (Sym- $\mathrm{H}<-100 \mathrm{nT})$.

The geomagnetic storms are selected based on their intensity and having its main phase duration less than $5 \mathrm{~h}$. Additionally, the Geotail satellite path, during the geomagnetic storm main phase, should be on the nightside to give a better insight into the nightside plasma sheet region. The corresponding quiet days are selected from the list of monthly quietest days available from the Kyoto website, such that Geotail satellite's position is in the nightside plasma sheet region. The satellite path during quiet and disturbed intervals is chosen to be nearly equal in order to ensure that the satellite position is not responsible for the observed compositional change. Table 1 enlists a total of eight intense $(\mathrm{Sym}-\mathrm{H}<-100 \mathrm{nT})$ and three moderate $(-100 \mathrm{nT}<$ Sym- $\mathrm{H}<-50 \mathrm{nT})$ 
Table 1 Intense and moderate geomagnetic storms during solar cycle 23 and 24

\begin{tabular}{llll}
\hline $\begin{array}{l}\text { Intense } \\
\text { events }\end{array}$ & Storm days & Quiet days & Satellite observation \\
\hline 1 & 10 Feb 1997 & 4-5 Feb 1997 & Geotail \\
2 & 24 Apr 2000 & 13 Apr 2000 & Geotail \\
3 & 06 Nov 2001 & 27 Nov 2001 & Geotail \\
4 & 20-21 Nov 2003 & 4-5 Nov 2003 & Geotail \\
5 & 28 May 2011 & 22-23 May 2011 & Geotail \\
6 & 05-06 Aug 2011 & 10-11 Aug 2011 & Geotail \\
7 & 30 Sep-01 Oct 2012 & 27-28 Oct 2012 & Geotail \\
8 & 17-18 Mar 2013 & 16 Mar 2013 & RBSP \\
9 & 01-02 June 2013 & 31 May 2013 & RBSP \\
10 & 17-18 Mar 2015* & 11-13 Mar 2015 & Geotail + RBSP \\
11 & 23 June 2015 & 21 Jun 2015 & RBSP \\
\hline
\end{tabular}

Asterisk (*) mark shows the special event having its main phase duration of nearly $15 \mathrm{~h}$

geomagnetic storms from solar cycle 23 and 24, which satisfies the above-mentioned criteria. The most recent severe magnetic storm on 17 March 2015 had a long main phase duration of about $15 \mathrm{~h}$. For this event, we are able to investigate the effect of the main phase duration on the plasma sheet ion composition. This event is verified with the simultaneous observations from RBSP measurements and Geotail. For each of the above events, we have calculated the energy density and differential flux for $\mathrm{H}^{+}, \mathrm{He}^{+}$and $\mathrm{O}^{+}$ions during main phase.

\section{Geotail data}

Geotail satellite was launched on 24 July 1992, having an elliptical orbit of 9-30 $R_{\mathrm{E}}$, with an inclination of nearly $9.5^{\circ}$ and an orbital period of approximately $125 \mathrm{~h}$ (Nishida 1994). Geotail carries an Energetic Particle and Ion Composition (EPIC) instrument (Schlemm et al. 1994) which consists of two sensors: the ion composition system (ICS) and the suprathermal ion composition spectrometer (STICS). In the present study, EPIC/STICS sensor data are used that provide the differential flux, mass and charge state of low-energy charged particles having an energy range of 9-210 keV/e in eight logarithmically spaced spectral points. The EPIC/STICS sensor has an angular coverage of nearly $4 \pi$ sr and about 30 ion species channel, of which only three channels corresponding to $\mathrm{H}^{+}, \mathrm{O}^{+}$and $\mathrm{He}^{+}$ions are used in this study. For every spin period $(\sim 3 \mathrm{~s})$, there is a change in the energy step, so one complete spectrum is obtained at the end of eight spin period $(\sim 24 \mathrm{~s})$. From each of these energy spectra, the energy densities for $\mathrm{H}^{+}, \mathrm{O}^{+}$and $\mathrm{He}^{+}$are calculated by a method proposed by Nosé et al. $(2001,2003)$. The energy densities obtained by the same method are averaged over $10 \mathrm{~min}$ interval for better statistics.

\section{RBSP data}

Recently, a specialized, twin RBSP mission (recently renamed the Van Allen Probes) was launched in 2012. To maintain the consistency with other Van Allen Probes instrument papers, we use here the RBSP acronym. It operates in the equatorial plane between perigee of $600 \mathrm{~km}$ and apogee of $5.8 R_{\mathrm{E}}$ with a $\sim 9 \mathrm{~h}$ orbit period. The spin period of the spacecraft is $\sim 12 \mathrm{~s}$, with its spin axis pointing nearly in the solar direction (Mauk et al. 2013). The RBSP spacecraft has several instruments of which we consider ECT-HOPE (Helium, Oxygen, Proton, and Electron) (Funsten et al. 2013). ECT-HOPE measures $\mathrm{H}^{+}, \mathrm{He}^{+}$, and $\mathrm{O}^{+}$ion differential flux using a time of flight mass spectrometer with channel electron multiplier detectors from $1 \mathrm{eV}$ to $50 \mathrm{keV} . \mathrm{H}^{+}$and $\mathrm{O}^{+}$ion flux data are obtained at nearly every $24 \mathrm{~s}$ because the HOPE instrument measures ions and electrons during alternate spins (Funsten et al. 2013). HOPE instrument comprises of 72 energy channels that are logarithmically spaced, with measurements in five directions relative to the spin axis and at 16 spin angles (Sarno-Smith et al. 2015). We have selected the geomagnetic storms such that both RBSP-A and RBSP-B have at least one of the probes located in the nightside sectors (i.e., 1800-0600 Magnetic Local Time (MLT) and crossed $L$ greater than or equal to 3.5 during the storm main phase. To estimate the storm time enhancements, the quiet days are considered when less magnetic disturbance is recorded in Kp index and the twin probe crosses the nightside sector.

The detailed observation of ion composition in the near-Earth plasma sheet and inner magnetosphere is given in the following sections.

\section{Analysis and results: Geotail and RBSP observations \\ Energy density and its ratio variation during intense geomagnetic storms}

The energy density of ions in the near-Earth plasma sheet is studied because (1) RBSP and Geotail cover the different regions in the near-Earth plasma sheet. (2) A quantitative analysis has been extended from the previous studies for other geomagnetic storms of solar cycle 23 and 24. (3) It contributes maximum to the high-energy portion of the ion population $(>20 \mathrm{keV})$ covered by the STICS energy band (Kistler et al. 1992). In order to observe the energy density and flux enhancement during intense geomagnetic storms, we study two examples of 20 November 2003 and 17 March 2015.

Figure 1 shows the largest geomagnetic storm of solar cycle 23 that occurred on 20 November 2003. This 

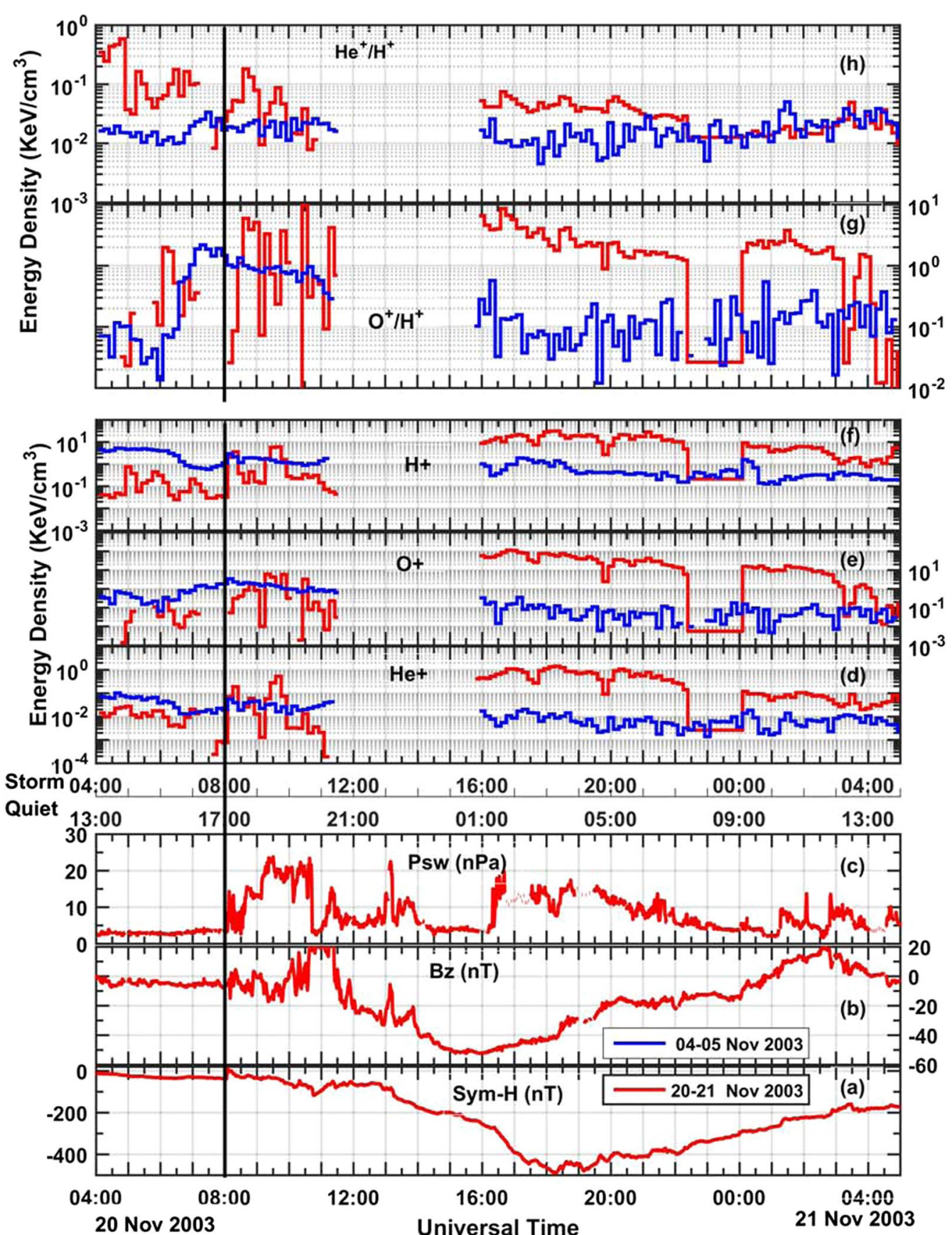

Fig. 1 Geomagnetic storm data from 20 November 20030400 UT to 21 November 20030500 UT, using Geotail satellite. a Sym-H, b, c interplanetary parameters (IMF Bz, $\left.\mathrm{P}_{\mathrm{sw}}\right), \mathbf{d ~ H e}{ }^{+}, \mathbf{e ~} \mathrm{O}^{+}, \mathbf{f} \mathrm{H}^{+}$ions energy density during storm (red) and quiet (blue) intervals, $\mathbf{g} \mathrm{O}^{+} / \mathrm{H}^{+}, \mathbf{h ~ H e} \mathrm{H}^{+} / \mathrm{H}^{+}$ energy density ratio. The black vertical line shows the time of storm sudden commencement (SSC)

geomagnetic storm is associated with the passage of a large magnetic cloud that originated from active region 0501 (Gopalswamy et al. 2005). The lower three panels in Fig. 1a-c show the Sym-H minimum of $-490 \mathrm{nT}$ at 1817 UT on 20 November 2003 and variations of interplanetary parameters like IMF $\mathrm{Bz}$ and solar wind dynamic pressure (Psw), respectively, during the magnetic storm period. The time interval shown here is for about 25 - $h$ duration from 0400 UT on 20 November 2003 to 0500 UT on 21 November 2003. The main phase duration is of nearly $5 \mathrm{~h}$, during which the average intensity of IMF $\mathrm{Bz}$ remains constantly southward at almost $-40 \mathrm{nT}$ 
having peak intensity of $-52 \mathrm{nT}$ and Psw reaching nearly $20 \mathrm{nPa}$. The Geotail orbit path has been carefully checked during the main phase of the geomagnetic storm and was located at $\left(X_{\mathrm{GSM}}, Y_{\mathrm{GSM}}\right)=(-9,-3) \mathrm{R}_{\mathrm{E}}$ during the Sym-H minimum (not shown here).

Figure $1 \mathrm{~d}-\mathrm{f}$ depicts the energy density measured from Geotail spacecraft, for $\mathrm{He}^{+}, \mathrm{O}^{+}$and $\mathrm{H}^{+}$ions, respectively. The top two panels show its ratio $\mathrm{O}^{+} / \mathrm{H}^{+}$and $\mathrm{He}^{+} /$ $\mathrm{H}^{+}$(Fig. 1g, h), and the black vertical line shows the sudden commencement (SC) of the storm. The red and blue curves (Fig. 1d-h) stand for the geomagnetic storm and the corresponding quiet interval. The quiet interval corresponds to 1300 UT on 04 November 2003 to 1400 UT on 05 November 2003. A gap in Fig. 1d-h is observed due to satellite's exit from the plasma sheet which does not give any information about ion composition. The ion species, $\mathrm{He}^{+}, \mathrm{O}^{+}$and $\mathrm{H}^{+}$ions, clearly shows the maximum enhancement during the main phase of the storm, especially during the interval (1600-2200 UT) on 20 November 2003 and then slowly reducing in its recovery phase. The average values of energy density $(\langle\varepsilon\rangle)^{1}$ at the storm main phase (1600-2200 UT) and corresponding quiet intervals were $\left\langle\varepsilon_{\mathrm{H}+}\right\rangle_{\mathrm{S}}=16.9703 \mathrm{keV} /$ $\mathrm{cm}^{3}, \quad<\varepsilon_{\mathrm{H}+}>_{\mathrm{Q}}=0.681 \mathrm{keV} / \mathrm{cm}^{3}$ for $\mathrm{H}^{+}$and $<\varepsilon_{\mathrm{He}+}>_{\mathrm{S}}=0.721 \mathrm{keV} / \mathrm{cm}^{3},\left\langle\varepsilon_{\mathrm{He}+}>_{\mathrm{Q}}=0.0078 \mathrm{keV} / \mathrm{cm}^{3}\right.$ for $\mathrm{He}^{+}$, where subscript $\mathrm{S}$ and $\mathrm{Q}$ indicates the storm and quiet intervals, respectively. The ion composition of $\mathrm{O}^{+}$ ions shows a drastic change in the energy density from the storm time $\left.\left(<\varepsilon_{\mathrm{O}+}\right\rangle_{\mathrm{S}}=47.3279 \mathrm{keV} / \mathrm{cm}^{3}\right)$ to the quiet time $\left(<\varepsilon_{\mathrm{O}+}>_{\mathrm{Q}}=0.0762 \mathrm{keV} / \mathrm{cm}^{3}\right)$.

To determine the extent of enhancement in the ionospheric species $\left(\mathrm{O}^{+}\right.$and $\left.\mathrm{He}^{+}\right)$during varying interplanetary conditions, the ratio of energy densities for $\mathrm{He}^{+} / \mathrm{H}^{+}$ and $\mathrm{O}^{+} / \mathrm{H}^{+}$is taken. The energy density ratio for $\mathrm{He}^{+} /$ $\mathrm{H}^{+}$shows less enhancement from quiet to storm time $\left(<\varepsilon_{\mathrm{He}+/ \mathrm{H}_{+}}\right\rangle_{\mathrm{Q}}=0.0172$ to $\left.\left\langle\varepsilon_{\mathrm{He}+/ \mathrm{H}+}\right\rangle_{\mathrm{S}}=0.0424\right)$, while the energy density ratio for $\mathrm{O}^{+} / \mathrm{H}^{+}$enhances drastically from $\left.<\varepsilon_{\mathrm{O}+/ \mathrm{H}+}\right\rangle_{\mathrm{Q}}=0.732$ to $\left\langle\varepsilon_{\mathrm{O}+/ \mathrm{H}+}\right\rangle_{\mathrm{S}}=2.8556$.

On the other hand, Fig. 2 shows the largest geomagnetic storm of solar cycle 24, i.e., 17 March 2015, following double-halo coronal mass ejections (CMEs) hitting the Earth's magnetosphere reaching to a minimum Sym-H of $-234 \mathrm{nT}$ at 2247 UT on 17 March 2015 (Fig. 2a) with the Geotail position in the $\left(X_{\mathrm{GSM}}\right.$, $\left.Y_{\mathrm{GSM}}\right)=(-3,9) \quad R_{\mathrm{E}}$. The panel representations of Fig. 2 are same as Fig. 1, and the vertical line gives the time of $\mathrm{SC}$ at $0445 \mathrm{UT}$. Figure $2 \mathrm{~d}-\mathrm{f}$ represents the enhancement in the energy densities for $\mathrm{He}^{+}, \mathrm{O}^{+}$and $\mathrm{H}^{+}$ions during

\footnotetext{
${ }^{1}$ Average value of energy density $\langle\varepsilon\rangle$, average values of energy density at the storm main phase is $\left\langle\varepsilon_{\mathrm{H}+}\right\rangle_{\mathrm{S}}$, average values of energy density at the Quiet interval is $\left\langle\varepsilon_{\mathrm{H}+}>\mathrm{Q}\right.$.
}

the storm main phase, with slightly fluctuating $\mathrm{Bz}$, reaching to $-25 \mathrm{nT}$ at $1307 \mathrm{UT}$ and Psw peaking to nearly $40 \mathrm{nPa}$ at $1350 \mathrm{UT}$. It is observed that the enhancement in energy density is higher for $\mathrm{O}^{+}$ions than $\mathrm{H}^{+}$or $\mathrm{He}^{+}$at 1800-0200 UT, while the composition of all three species is shown by blue curve during the quiet intervals. $\mathrm{O}^{+}$ion shows the drastic enhancement from $\left\langle\varepsilon_{\mathrm{O}+}\right\rangle_{\mathrm{Q}}=0.52 \mathrm{keV} /$ $\mathrm{cm}^{3}$ to $\left\langle\varepsilon_{\mathrm{O}+}\right\rangle_{\mathrm{S}}=3.8 \mathrm{keV} / \mathrm{cm}^{3}$. Figure $2 \mathrm{~g}$ shows the enhancement in the energy density ratio of $\mathrm{O}^{+} / \mathrm{H}^{+}$ions from quiet to storm interval with $\left\langle\varepsilon_{\mathrm{O}+/} \varepsilon_{\mathrm{H}+}\right\rangle_{\mathrm{Q}}=0.1061$ and $\left\langle\varepsilon_{\mathrm{O}+} \varepsilon_{\mathrm{H}+}\right\rangle_{\mathrm{S}}=1.3326$, while $\mathrm{He}^{+} / \mathrm{H}^{+}$energy density ratio does not vary (Fig. 2h). For 20 November 2003 geomagnetic storm, the overall enhancement in $\mathrm{O}^{+}$ion energy density is 10.72 times greater than during the 17 March 2015 event. Table 2 represents the energy density of the individual species along with their ratio observed by Geotail and RBSP for the intense and moderate geomagnetic storms.

For a given geomagnetic storm, the minimum value of Sym- $\mathrm{H}$ along with the main phase duration and time are shown in Table 2 . The interplanetary parameters, like the peak value of southward IMF $\mathrm{Bz}(\mathrm{nT})$ and its duration in hours along with the maximum value of Psw $(\mathrm{nPa})$ and the corresponding energy densities for $\mathrm{H}^{+}, \mathrm{O}^{+}$and $\mathrm{He}^{+}$ ions, are shown. The observations are taken using Geotail spacecraft for geomagnetically quiet and disturbed intervals. Similar analysis is carried out for the largest proton event (in terms of particles above $40 \mathrm{MeV}$ range), i.e., 06 November 2001 geomagnetic storm (not shown in figure). Owing to the high injection rate of the energetic particles in the interplanetary medium, there arises a spacecraft anomaly. During this period, solar wind velocities from ACE/WIND satellites were degraded and could not be obtained during peak activity (Alex et al. 2005). So, Vsw is absent in Table 2. A detailed analysis of the dependence of plasma sheet energy density and interplanetary parameters is carried out in this study.

For 17 March 2015 event, we have studied the energy density variations in the near-Earth plasma sheet and inner magnetosphere using Geotail and RBSP spacecraft. This event is very important to investigate as it provides energy density variation at different $L$ values with observations from both satellites. The direct measurements of energy density of ionospheric ions $\mathrm{O}^{+}, \mathrm{H}^{+}$and $\mathrm{He}^{+}$are not available; hence, the product of ion partial density $(n)$ and ion temperature (T) from the RBSP observations are used as a proxy for the energy density (https://www. rbsp-ect.lanl.gov/science/DataDirectories.php). Figure 3 depicts the Sym-H and IMF Bz variations for the period of 17-18 March 2015 (48 h). Figure 3a illustrates the energy density ratio for $\mathrm{O}^{+} / \mathrm{H}^{+}$(red) and $\mathrm{He}^{+} / \mathrm{H}^{+}$ (blue) measured using RBSP-A. The yellow dashed line represents the $L$ value of the spacecraft trajectory. The 

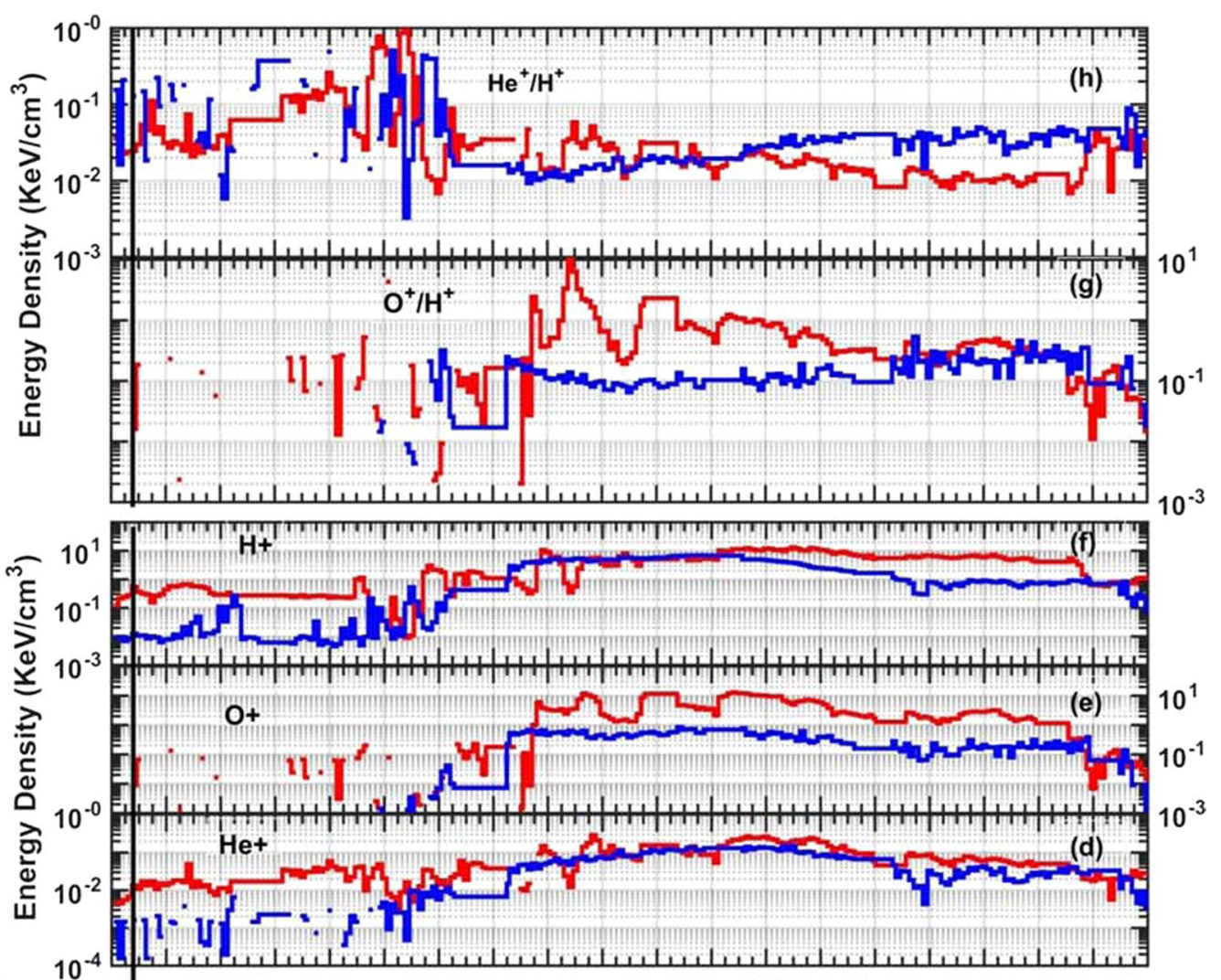

$\begin{array}{llllllllll}\text { Storm 04:0p, } & 08: 00 & 12: 00 & 16: 00,20: 00,00: 00,04: 00 & 08: 00,12: 00,16: 00 \\ \text { Quiet 22:0p } & 02: 00 & 06: 00 & 10: 00 & 14: 00 & 18: 00 & 22: 00 & 02: 00 & 06: 00 & 10: 00\end{array}$

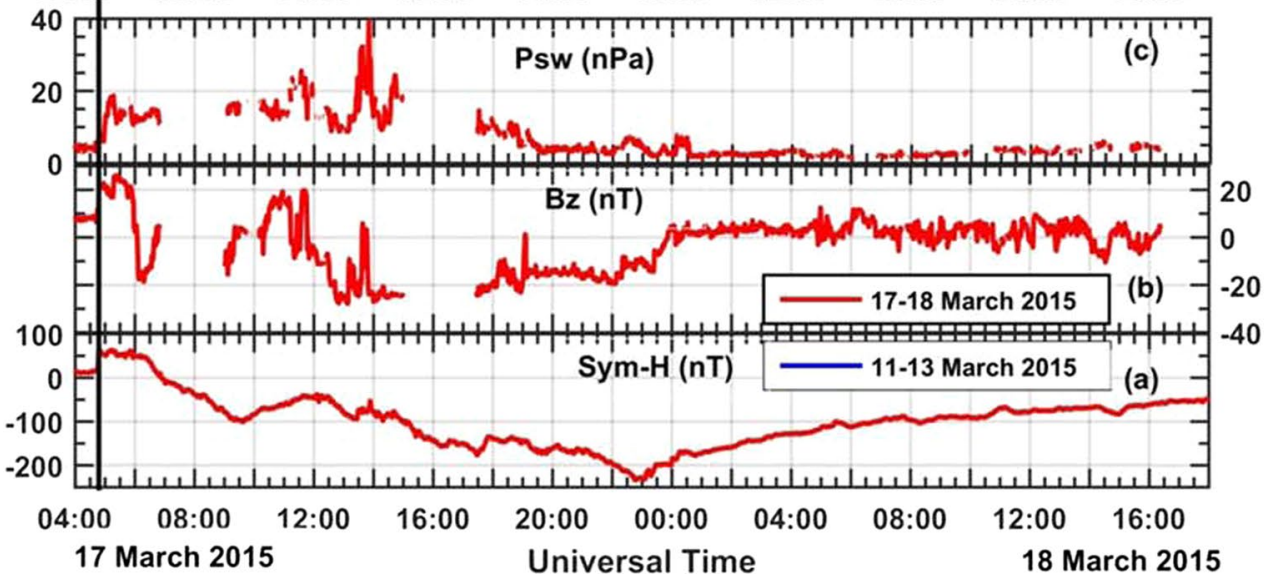

Fig. 2 Same as Fig. 3 except for 17 March 2015

data gap observed in Fig. 3a is due to motion of spacecraft below $L=3.5$. This ensures that the satellite is completely immersed into the inner magnetosphere. It can be observed that the energy density increases with the increase in intensity of the geomagnetic storm. Moreover, the $\left\langle\varepsilon_{\mathrm{O}+/} \varepsilon_{\mathrm{H}+}>\right.$ ratio is about 170 and $\left\langle\varepsilon_{\mathrm{He}}^{+} / \varepsilon_{\mathrm{H}+}>\right.$ ratio is about 10 during the geomagnetic storm main phase (1800-0200 UT).
During main phase, it is observed that $\mathrm{He}^{+} / \mathrm{H}^{+}$ energy density ratio peaks at $L=5$, while $\mathrm{O}^{+} / \mathrm{H}^{+}$ remains high at all $L$ values. During Sym- $\mathrm{H}$ minimum, the $\mathrm{O}^{+} / \mathrm{H}^{+}$ratio is not observed because the spacecraft trajectory is at $L<3.5$. However, the observed enhancement in the $\mathrm{O}^{+} / \mathrm{H}^{+}$energy density ratio, using RBSP, is maximum for 17 March 2015, among all the geomagnetic storms of solar cycle 24 considered in our study 


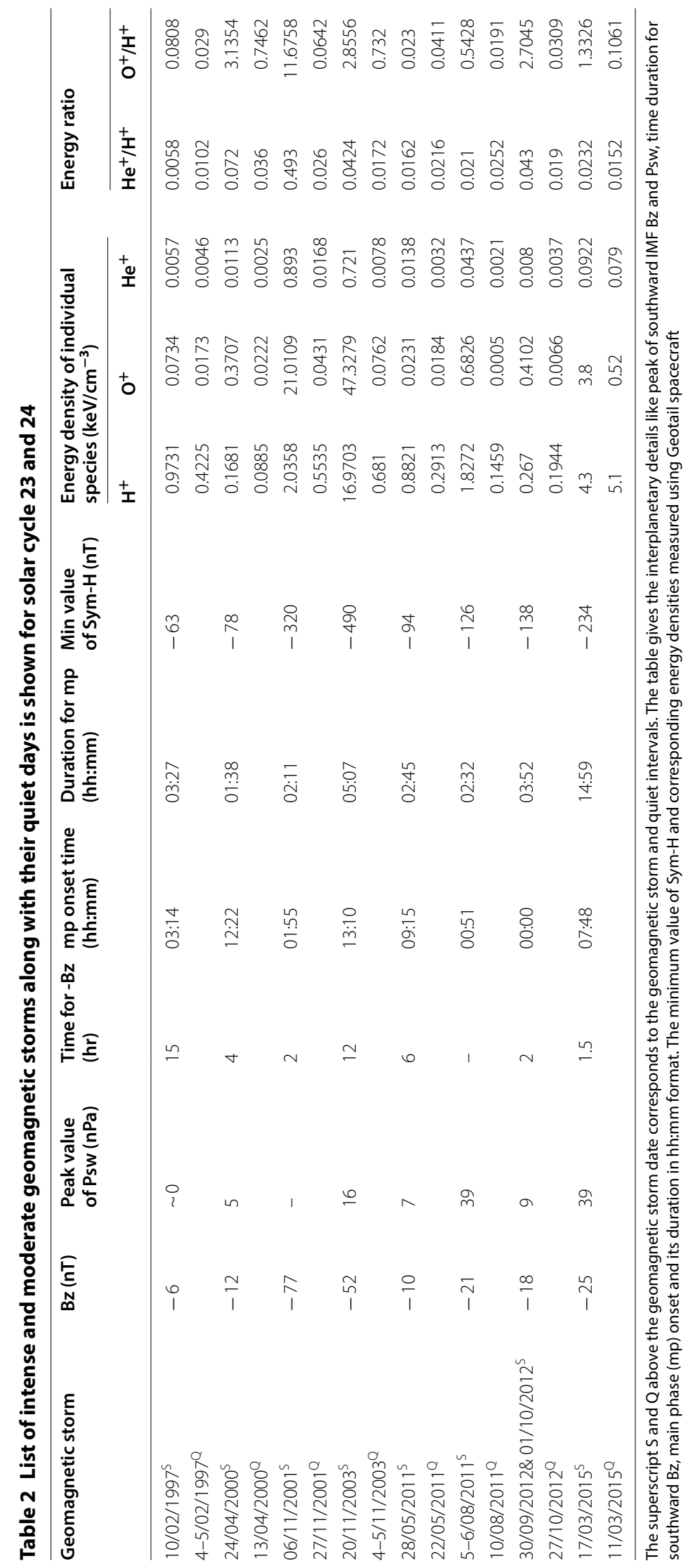




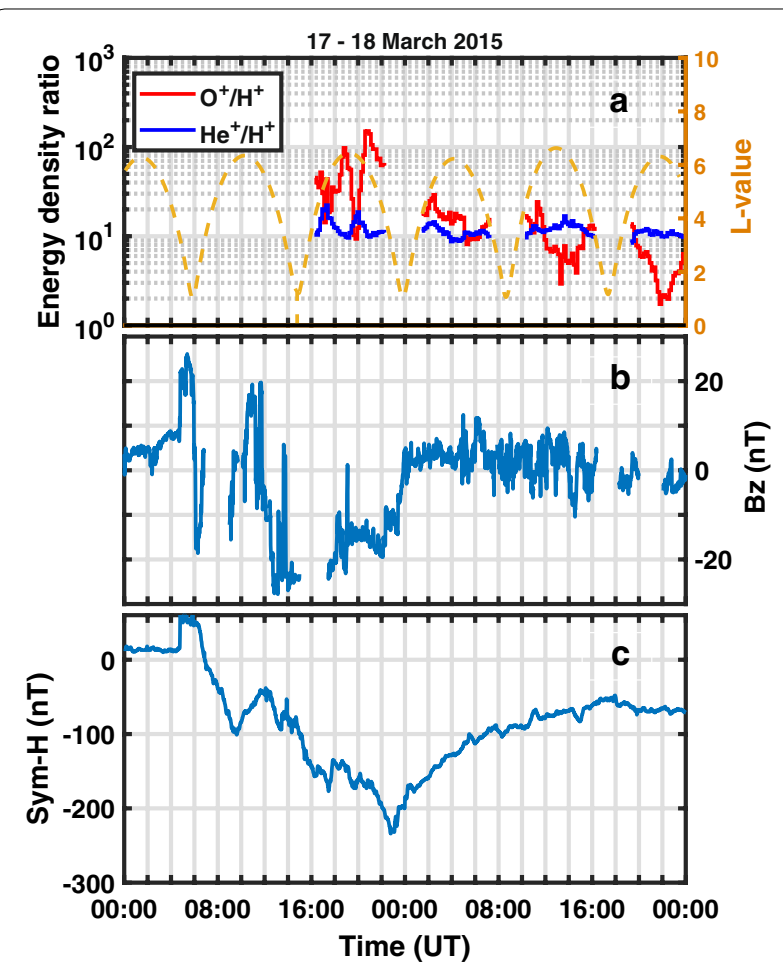

Fig. 3 a Energy density for $\mathrm{O}^{+} / \mathrm{H}^{+}$(red) and $\mathrm{He}^{+} / \mathrm{H}^{+}$(blue) for 17-18 March 2015 is shown using RBSP-A, b IMF Bz, c Sym-H

and is therefore shown as an example. In fact, a few magnetic storms of solar cycle 24 are also analyzed using RBSP data and the enhancement of $\mathrm{O}^{+} / \mathrm{H}^{+}$and
$\mathrm{He}^{+} / \mathrm{H}^{+}$energy density ratios is noticed. For an intense geomagnetic storm of 23 June 2015, the energy density ratios of $\mathrm{O}^{+} / \mathrm{H}^{+}$and $\mathrm{He}^{+} / \mathrm{H}^{+}$are 1.2596 and 1.1623 .

\section{Energy spectra}

The plasma sheet energy density of the ionospheric ions like $\mathrm{O}^{+}$and $\mathrm{He}^{+}$becomes higher than solar wind ions, i.e., $\mathrm{H}^{+}$, during the storm interval giving enhancement in the $\mathrm{He}^{+} / \mathrm{H}^{+}$and $\mathrm{O}^{+} / \mathrm{H}^{+}$ratio (Nosé et al. 2003). Energy density becomes larger if the particle temperature increases or particles undergo acceleration (it is marked by hardening of the energy spectrum). The energy density increase can also be owed to the shifting of the energy spectrum to the higher energy fluxes thereby giving an increased number density. The energy spectra are analyzed to determine the cause of ionospheric energy density enhancement.

Figure $4 \mathrm{a}, \mathrm{b}$ shows the energy spectra for $\mathrm{H}^{+}$and $\mathrm{O}^{+}$ ions using Geotail observations, during 20 November 2003 at the storm main phase (1720-1820 UT (red)), before the storm (0200-0400 UT (green)) and 21 November 2003 after the storm (0600-0700 UT (blue)). The time interval corresponding to each is given by a horizontal bar in Sym-H (Fig. 4c). Figure 4d shows the energy spectra for $\mathrm{H}^{+}$(cyan), $\mathrm{O}^{+}$(yellow) and $\mathrm{He}^{+}$ (magenta) flux-during the main phase period. It is obvious that during the main phase of geomagnetic storms, $\mathrm{H}^{+}$and $\mathrm{O}^{+}$ion flux becomes enhanced than pre-storm and post-storm intervals. Figure $4 \mathrm{~d}$ gives the
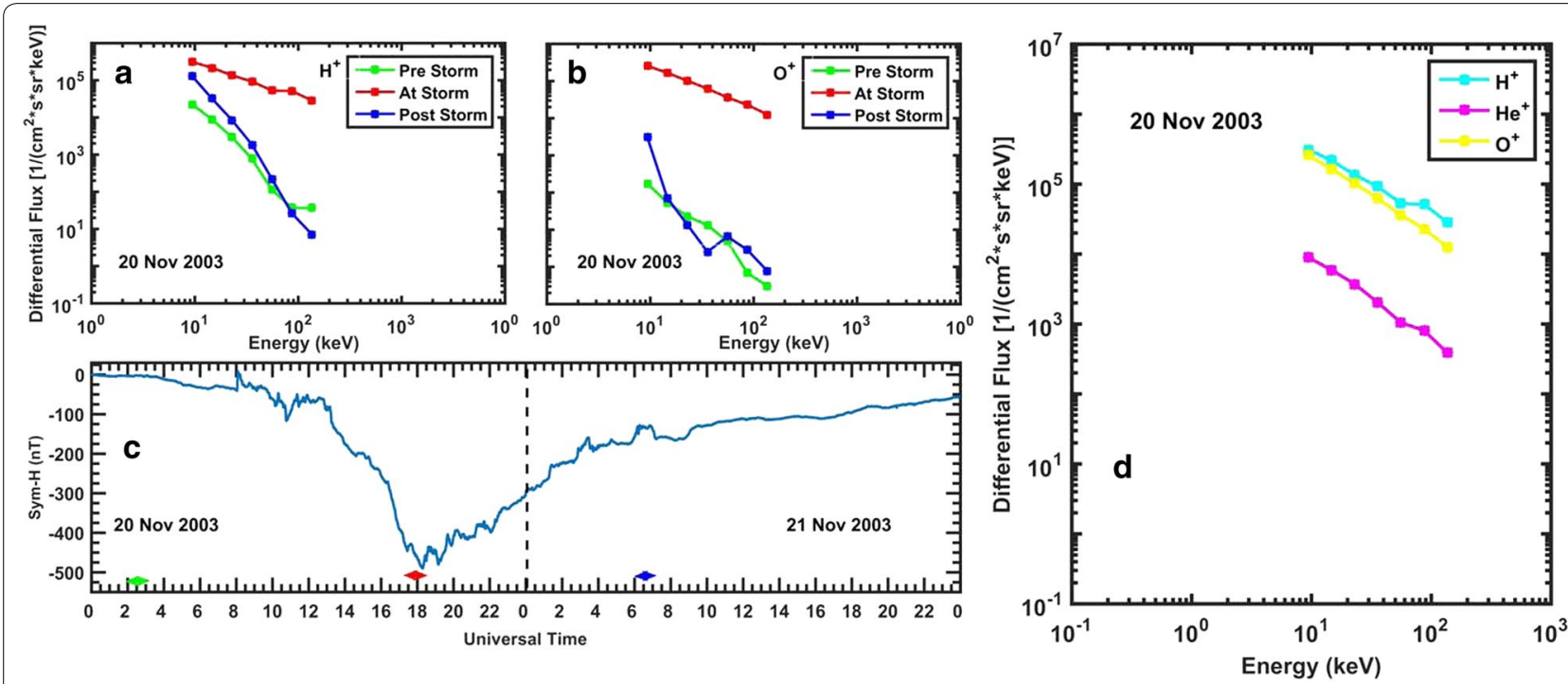

Fig. 4 Differential flux measured using Geotail satellite, at different energies for 20-21 November 2003 at different phase of the storm for $\mathbf{a} \mathrm{H}^{+}$and b $\mathrm{O}^{+}$c the corresponding time interval for pre-storm (green (0200-0400 UT), post-storm (blue (0600-0700 UT)) and main phase (red (1720-1820 UT)) is shown with the progress of geomagnetic storm $\mathbf{d}$ differential flux change with respect to energy at main phase of the storm for $\mathrm{H}^{+}, \mathrm{He}^{+}$and $\mathrm{O}^{+}$ions 

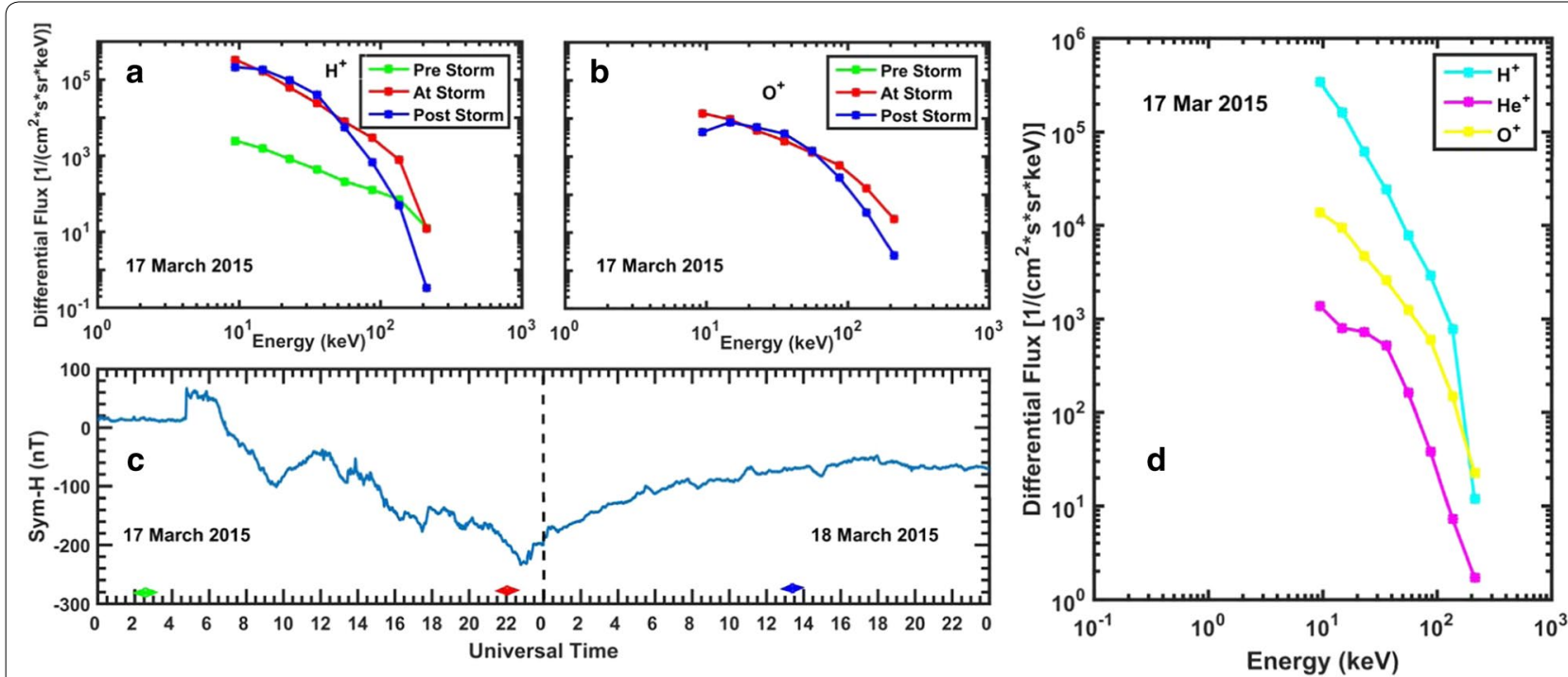

Fig. 5 Same as Fig. 4 using Geotail observations, except for 17 March 2015 storm having pre-storm interval 0200-0300 UT, post-storm interval 1200-1300 UT and main phase at 2150-2250 UT

flux enhancement for each ions and their subsequent acceleration at the storm main phase. $\mathrm{H}^{+}$and $\mathrm{O}^{+}$fluxes are almost equally enhanced for 20 November 2003 marked by the hardening of the spectra giving acceleration of the ions, which will be discussed in further sections.

Similarly, Fig. 5a-d shows the energy spectra for the geomagnetic storm of 17 March 2015 in the same manner as depicted in Fig. 4a-d using Geotail observations. Figure $5 \mathrm{a}, \mathrm{b}$ shows a moderate enhancement for $\mathrm{H}^{+}$and $\mathrm{O}^{+}$ions at its main phase (2150-2250 UT) than the prestorm (0200-0400 UT) and post-storm intervals (1200$1300 \mathrm{UT}$ ), respectively. There is no $\mathrm{O}^{+}$ion flux recorded before the storm and hence we do not obtain any spectra for pre-storm interval for $\mathrm{O}^{+}$ions. Figure $5 \mathrm{~d}$ clearly shows that the $\mathrm{O}^{+}$ions are accelerated to a lesser extent (marked by hardening of the spectra) than 20 November 2003 storm. On the other hand, $\mathrm{H}^{+}$ion flux is highest at the storm main phase. The most common feature that is observable in both the geomagnetic storms is hardening of $\mathrm{H}^{+}$and $\mathrm{O}^{+}$ion spectra at the storm main phase. The $\mathrm{O}^{+}$ion spectral hardening, shown in Fig. 4, is maximum for 20 November 2003, indicating the maximum acceleration of the plasma sheet ions outflowing from the ionosphere. On the other hand, for 17 March 2015, a little hardening or no hardening is observed, giving lesser extent of acceleration.

It is interesting to verify the energy spectra of $\mathrm{O}^{+}$flux enhancement during 17 March 2015 on the energy-time spectrograms using HOPE instrument on-board RBSP which gives more information of ion flux in the inner magnetosphere. Figure 6a shows ion energy spectra in the inner magnetosphere, observed by RBSP spacecraft for a geomagnetic storm during 16-19 March 2015. The duration of 4 days includes the pre-storm days, which can be considered as a quiet interval. From top to bottom, the panels displayed are the energy-time spectrogram giving a spin-averaged differential flux for $\mathrm{H}^{+}, \mathrm{He}^{+}, \mathrm{O}^{+}$ions for RBSP-A and RBSP-B, solar wind dynamic pressure, IMF $\mathrm{Bz}$ and Sym-H, respectively. Blue vertical dashed lines correspond to an interval of each day from 0000 UT on 16 March 2015 to 2400 UT on 19 March 2015. RBSP-A was positioned well on the nightside during the storm main phase and hence the spectrogram shows a great change in the ion flux during different intervals of geomagnetic disturbance. During the quiet time interval of 16 March 2015, the $\mathrm{O}^{+}$and $\mathrm{He}^{+}$ion flux, measured from RBSP-A, varies in the range of $10^{3}-10^{4} / \mathrm{cm}^{2}-\mathrm{s}-\mathrm{sr}-\mathrm{keV}$ at the higher energy channels (i.e., $>10^{3} \mathrm{eV}$ ). The data gap observed approximately after every $5 \mathrm{~h}$ corresponds to the period of perigee (Ferradas et al. 2016). As observed in Fig. 6a, before onset of geomagnetic storm, $\mathrm{H}^{+}$ion flux is already present due to proton-rich plasma coming from the solar wind and getting trapped in the Earth's magnetosphere at all the energy channels. On the other hand, the $\mathrm{O}^{+}$and $\mathrm{He}^{+}$ion flux is very less. With the onset of the geomagnetic storm, the $\mathrm{keV}$ ion fluxes for $\mathrm{O}^{+}$and $\mathrm{He}^{+}$begin to increase while there is only a little difference in $\mathrm{H}^{+}$flux before and during the storm for higher energy channels. This incoming flux at $\mathrm{keV}$ range shows the injection of plasma into the inner magnetosphere during the main phase of the geomagnetic storm. The 

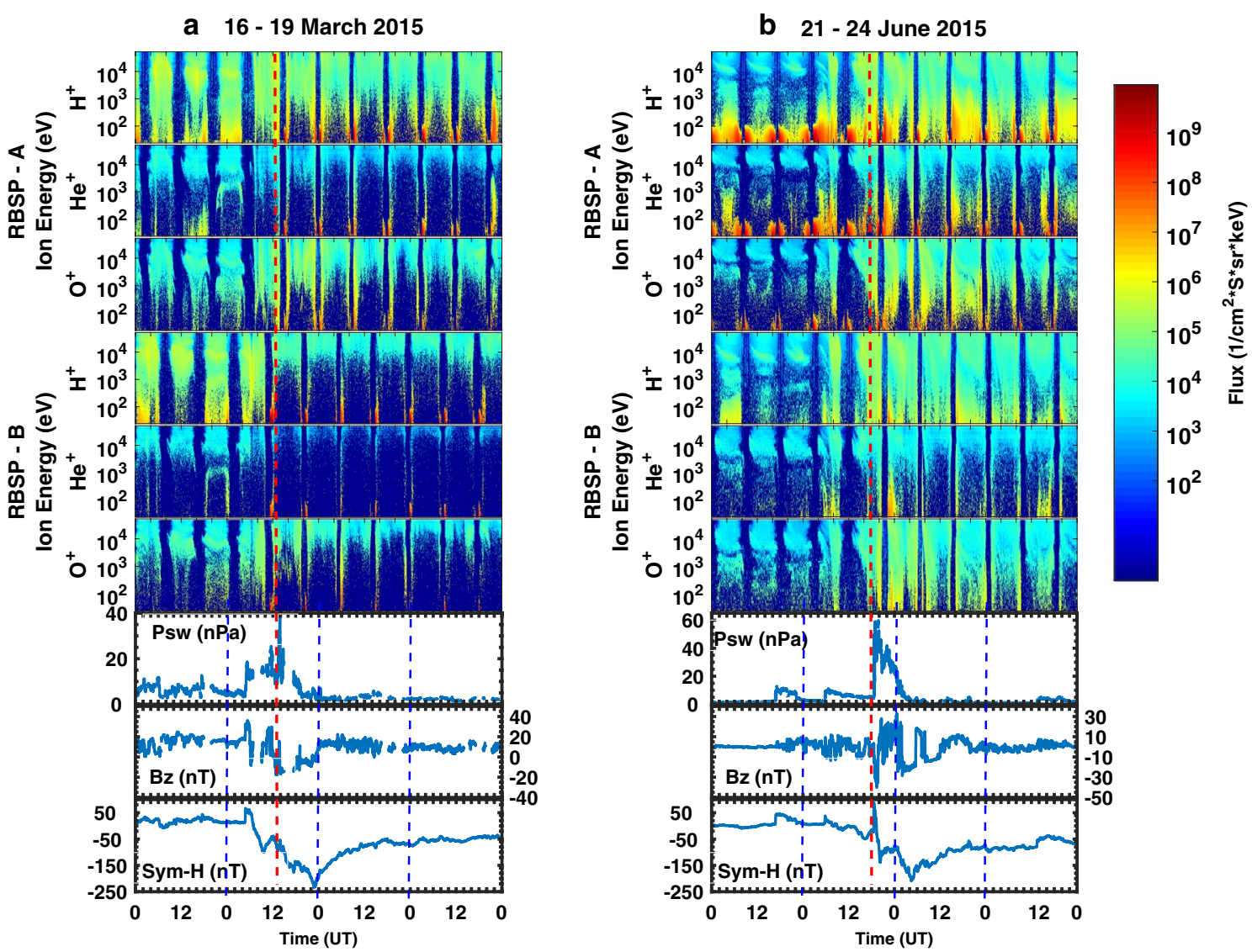

Fig. 6 Energy-time spectra for $\mathrm{H}^{+}, \mathrm{O}^{+}$and $\mathrm{He}^{+}$from RBSP-A (top three panels), RBSP-B (middle three panels) and plots in the lower three panels are solar wind dynamic pressure, IMF Bz and Sym-H for a 16-19 March 2015 b 21-24 June 2015. Black vertical line shows the time of SSC while the blue vertical lines correspond to each day interval

third panel from the top shows $\mathrm{O}^{+}$ion flux enhancement (roughly by two orders from $10^{3} / \mathrm{cm}^{2}$-s-sr-keV to $10^{5} / \mathrm{cm}^{2}$-s-sr-keV). The energy density of $\mathrm{O}^{+}$ion peaks to its maximum, at peak values of Psw $(\sim 40 \mathrm{nPa})$ and IMF $\mathrm{Bz}(-20 \mathrm{nT})$, as shown by red vertical line in Fig. $6 \mathrm{a}$. The central three panels correspond to the observations from RBSP-B. Since RBSP-B is identical to RBSP-A, it observes changes in the inner magnetosphere through both space and time. However, RBSP-B was on the dayside of the magnetosphere during the main phase of both the storms, so we could not observe such strong effects in RBSP-B (Fig. 6a, b). The same analysis is shown below for other intense geomagnetic storms of solar cycle 24, using only RBSP spacecraft.

Figure $6 \mathrm{~b}$ is same as Fig. 6a but for an intense geomagnetic storm of 21-24 June 2015 with minimum Sym-H peaking to $-208 \mathrm{nT}$ at 0424 UT on 23 June 2015. It can be observed that on 21 June 2015, when geomagnetic conditions are quiet, the recorded flux of each ion species on both the probes is of the order of $10^{3} / \mathrm{cm}^{2}$-s-sr-keV, at higher energy channels. At the time of SSC, Psw increased suddenly from nearly $5 \mathrm{nPa}$ to $59 \mathrm{nPa}$ while the IMF $\mathrm{Bz}$ was down to $-38 \mathrm{nT}$. This led to an enhancement in the ion flux throughout the given energy range at 1859 UT on 22 June 2015 (marked by red vertical line). The top three panels show the measurements through RBSP-A depicting the $\mathrm{H}^{+}$ion flux enhancement from $10^{3}$ to $10^{5} / \mathrm{cm}^{2}-\mathrm{s}-\mathrm{sr}-\mathrm{keV}$ while the $\mathrm{O}^{+}$ion flux tremendously increased from $10^{2} / \mathrm{cm}^{2}-\mathrm{s}$ sr-keV to $10^{6} / \mathrm{cm}^{2}$-s-sr-keV. Probe B following Probe A also shows the flux enhancement for each ion species. A similar enhancement is observed for the intense geomagnetic storms of 01-02 June 2013 and 17-18 March 2013, which are not shown but listed in Table 1.

Additionally, the analysis of other moderate geomagnetic storms is studied in similar manner using Geotail spacecraft. $\mathrm{O}^{+}$ions undergo similar acceleration for moderate geomagnetic storms and its corresponding energy densities are mentioned in Table 2. The importance of enhanced energy spectra in the inner magnetosphere and related mechanisms is discussed in the later sections. 

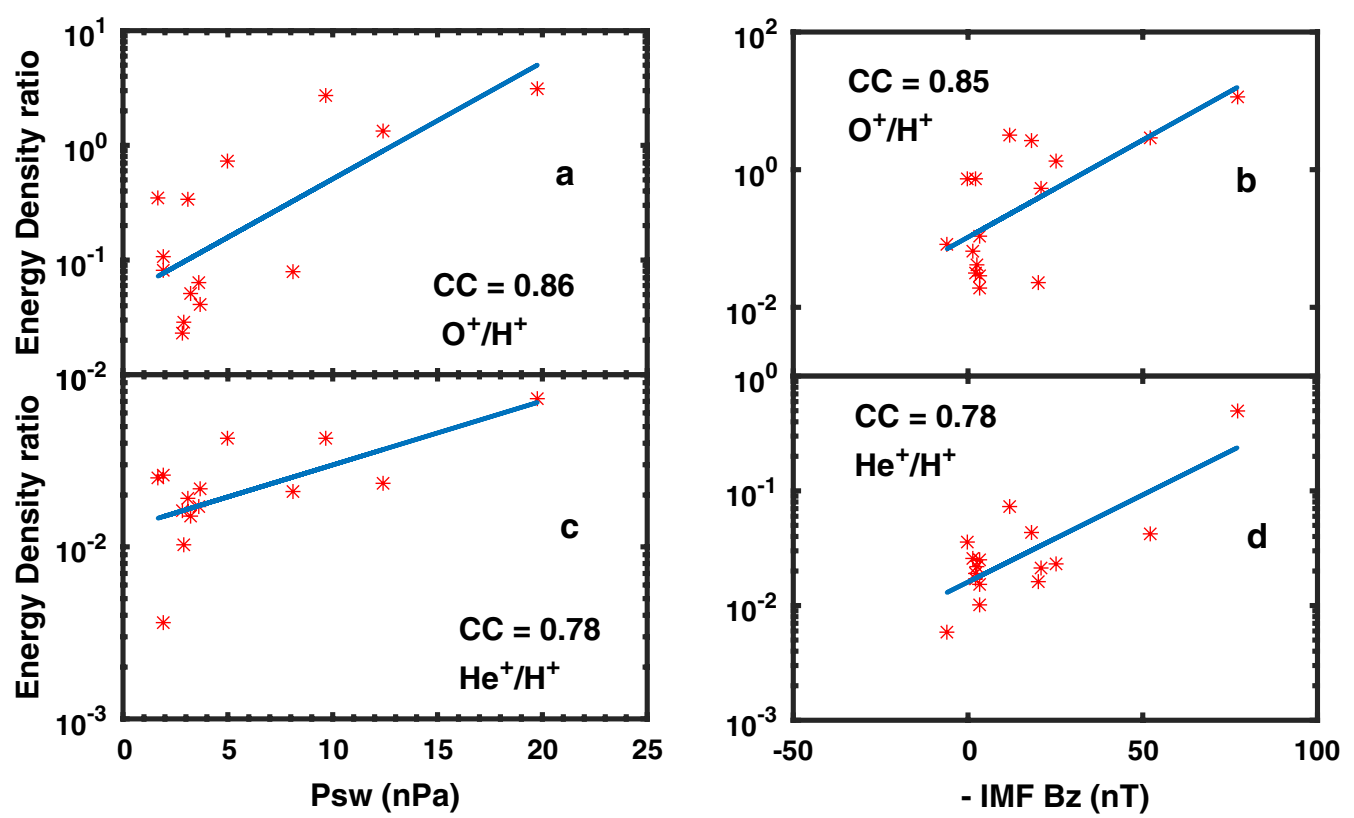

Fig. 7 The correlation analysis of IMF Bz and Psw with the energy density ratio $\mathrm{O}^{+} / \mathrm{H}^{+}$and $\mathrm{He}^{+} / \mathrm{H}^{+}$

\section{Role of IMF Bz and solar wind dynamic pressure in energy density variations}

The southward IMF Bz and solar wind dynamic pressure are very important in controlling the dynamics of the magnetosphere. So, it is worthwhile to understand the role of interplanetary conditions in driving plasma sheet dynamics during the geomagnetic storms. The Earth's magnetosphere responds very quickly to the change in magnitude and orientation of IMF $\mathrm{Bz}$ that enhances the convection electric field. Compression of the Earth's magnetosphere accounts for the global changes in the magnetosphere and ionosphere system, due to enhanced solar wind dynamic pressure (Zesta et al. 2013). Magnetic energy stored in the magnetosphere (or magnetotail) is transported to the inner magnetosphere through the plasma sheet region. So, the changes in the plasma sheet ion composition will affect the inner magnetospheric composition. During a geomagnetic storm, the plasma sheet ion composition is mainly influenced by the solar wind dynamic pressure and southward IMF Bz. Figure 6a shows the sudden increase in Psw at 1100 UT on 17 March 2015, and in Fig. 6b, it is observed at 1840 UT on 22 June 2015. The observed Psw increase continues to be at high values during the main phase of the storm. When high Psw impacted the magnetosphere, it caused a huge outrush of the ionospheric ions and remained high throughout the geomagnetic storm main phase. Figure 7a, b shows the correlation between Psw with energy density ratio of $\mathrm{O}^{+} / \mathrm{H}^{+}$and $\mathrm{He}^{+} / \mathrm{H}^{+}$ions using Geotail observations in the near-Earth plasma sheet. It is clearly seen that the plasma sheet $\mathrm{H}^{+}, \mathrm{O}^{+}$and $\mathrm{He}^{+}$ion outflow is well correlated with Psw. The correlation coefficient of $\left\langle\varepsilon_{\mathrm{O}+/} \varepsilon_{\mathrm{H}+}>\right.$ and $\left\langle\varepsilon_{\mathrm{He}+/} \varepsilon_{\mathrm{H}+}>\right.$ with Psw is 0.86 and 0.78 , respectively. On the other hand, Fig. 7c, d shows that IMF $\mathrm{Bz}$ is the next important parameter giving ionospheric outflow. IMF $\mathrm{Bz}$ correlation with plasma sheet energy density ratio for $\mathrm{O}^{+} / \mathrm{H}^{+}$and $\mathrm{He}^{+} / \mathrm{H}^{+}$is 0.85 and 0.78 , respectively. So, Psw and IMF $\mathrm{Bz}$ are both equally crucial parameters giving rise to changes in plasma sheet ion composition.

\section{$L$ value dependence on energy density variations}

The energy density ratio of $\mathrm{O}^{+} / \mathrm{H}^{+}$and $\mathrm{He}^{+} / \mathrm{H}^{+}$is not constant at all $L$ values due to varying distance from the Earth and also varying intensity of the storm. So, in order to estimate $L$ value dependence of the energy density ratio with the strength of geomagnetic activity, we have plotted Fig. 8, wherein, the observations from Geotail and RBSP are considered and combined together. The open circle and open diamond correspond to the energy density ratio of $\mathrm{O}^{+} / \mathrm{H}^{+}$ from Geotail and RBSP, while closed circle and closed diamond correspond to the energy density ratio of $\mathrm{He}^{+} / \mathrm{H}^{+}$ from Geotail and RBSP, respectively. In $L=2-4$, the observations are taken from RBSP, while for $L>5$, the observations are taken from Geotail spacecraft. It can be observed that $\mathrm{O}^{+} / \mathrm{H}^{+}$and $\mathrm{He}^{+} / \mathrm{H}^{+}$are almost equally high (of the order of $10^{1}$ ) in the $\mathrm{L}$ range of $2-4$, while it decreases to lower energy range of $10^{-2}$ as the spacecraft moves to $L>5$. For the moderate to high geomagnetic activity of $\mathrm{Kp}=5-8$, the energy density ratio goes high in the $L$ range of $2-4$, 


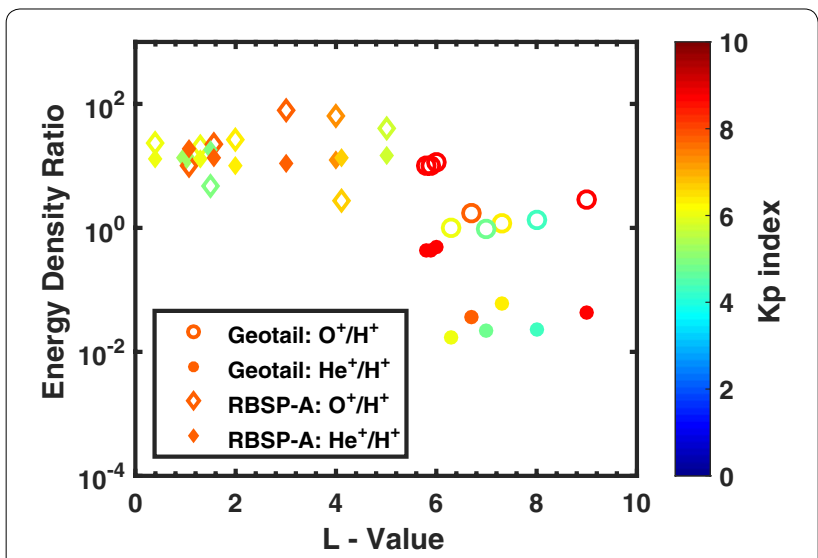

Fig. $8 \mathrm{~L}$ value dependence of energy density ratio with respect to Kp

while for the same strength of geomagnetic activity at $L>5$ the energy density ratio is low. It is important to notice that the enhancement in the energy density ratio of $\mathrm{O}^{+} / \mathrm{H}^{+}$and $\mathrm{He}^{+} / \mathrm{H}^{+}$is higher for RBSP observations than Geotail values of the order of almost 2 which explains the energization of ions in the near-Earth region. So, the energy density ratio for $\mathrm{O}^{+} / \mathrm{H}^{+}$and $\mathrm{He}^{+} / \mathrm{H}^{+}$peaks at $L=2-4$ while it decreases at $L>5$ for the same intensity of geomagnetic activity.

\section{Discussion}

The mechanisms like (1) energization of the ionospheric ions to ring current energies, (2) the change in plasma sheet ion composition and (3) the extent of compositional change observed during intense geomagnetic storms have not been completely understood. The transport and energization of ions are complex in nature and one of the important issues in storm time dynamics and plasma circulation in the inner magnetosphere (Denton et al. 2016). Through Geotail and RBSP observations, we find the energy density enhancement of $\mathrm{H}^{+}, \mathrm{O}^{+}$and $\mathrm{He}^{+}$ions during disturbed intervals. The energy density ratio for $\mathrm{O}^{+} / \mathrm{H}^{+}$and $\mathrm{He}^{+} / \mathrm{H}^{+}$is well correlated with Psw, southward IMF $\mathrm{Bz}$ and also depends on the $L$ values. Additionally, the studies by Nosé et al. (2003) have shown the probable dependence of the ionospheric outflow on the solar wind dynamic pressure.

Accelerated hot $\mathrm{O}^{+}$ions have its highest contribution to the ring current particles at the geomagnetic storm main phase (Hamilton et al. 1988) due to strong convection electric field and inflow of ions from the plasma sheet. Thus, plasma sheet has to become rich with $\mathrm{O}^{+}$ ions before and during the geomagnetic storm main phase for the ring current plasma to become rich with $\mathrm{O}^{+}$ ions, as observed in our studies (Figs. 1, 2, 3). Hence, the plasma sheet plays an important role in the development of the storm time ring current. The energy spectra for $\mathrm{H}^{+}, \mathrm{O}^{+}$and $\mathrm{He}^{+}$ions are plotted for geomagnetic storms of different intensities (Fig. 9a-c). The $\mathrm{O}^{+}$and $\mathrm{He}^{+}$ion flux spectra show a slight tendency of spectral hardening from moderate to the most intense magnetic storms (Fig. 9b, c). However, the hardest spectrum is observed for the most intense storm for all three ion species (Fig. 9a-c). In case of 6 November 2001, Sym-H (min) is $-320 \mathrm{nT}$ (cyan curve), the $\mathrm{He}^{+}$and $\mathrm{O}^{+}$ion flux at lower energies shoot up to its maximum, exceeding the flux of

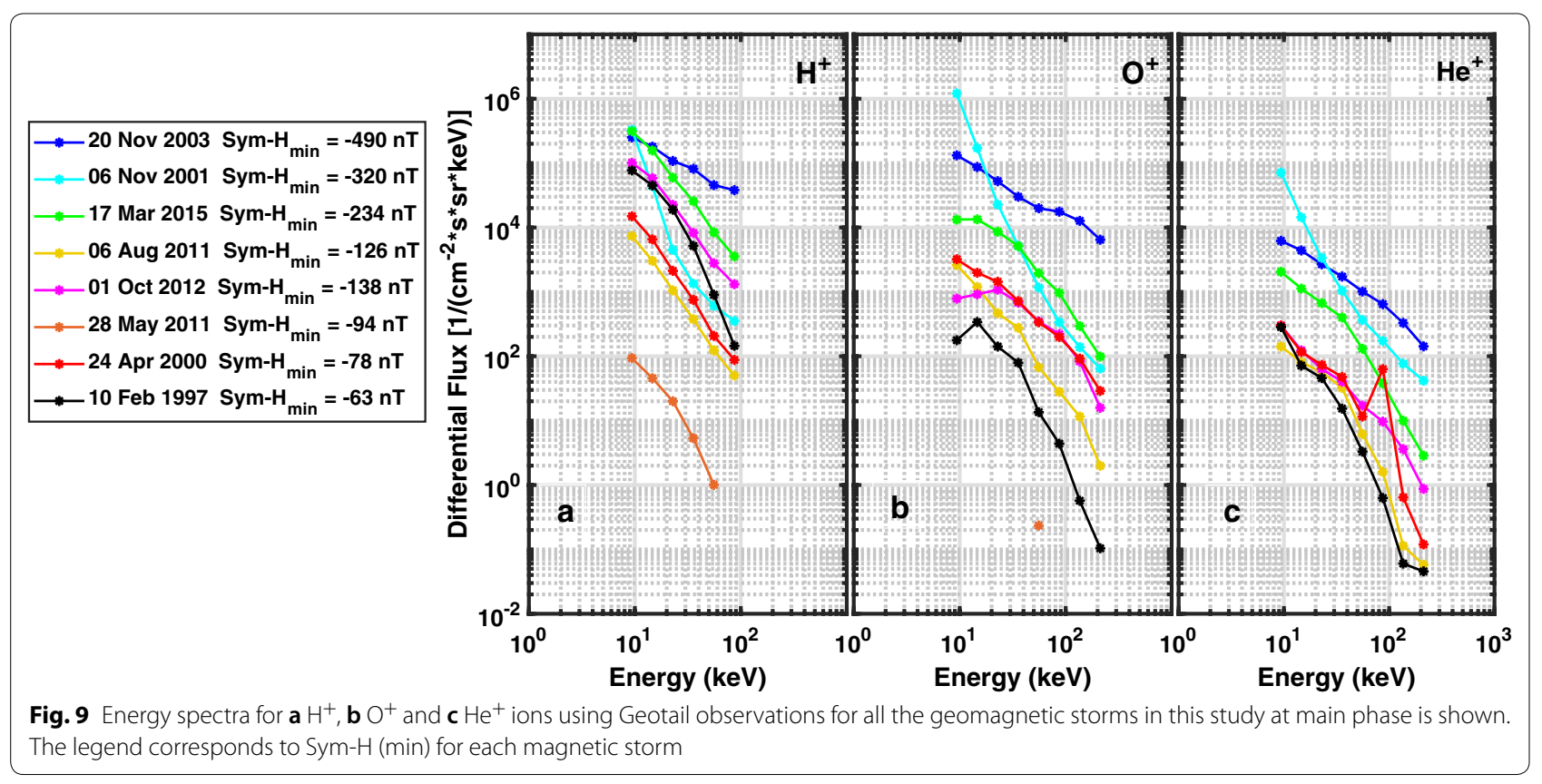


the most intense geomagnetic storm of solar cycle 23, i.e., 20 November 2003 (Sym-H $(\mathrm{min})=-490 \mathrm{nT}$, blue curve). The observed flux enhancement at $9.38 \mathrm{keV}$ on 6 November 2001 is maximum for $\mathrm{O}^{+}$ions $\left(1.208 \times 10^{6} /\right.$ $\mathrm{cm}^{2}$-s-sr-keV $)$ than $\mathrm{H}^{+}\left(3.294 \times 10^{5} / \mathrm{cm}^{2}\right.$-s-sr-keV $)$ and $\mathrm{He}^{+}\left(7.126 \times 10^{4} / \mathrm{cm}^{2}-\mathrm{s}-\mathrm{sr}-\mathrm{keV}\right)$. The possible reason for this could be the increased IMF Bz strength to $-77 \mathrm{nT}$ within $2 \mathrm{~h}$. On the contrary, for 20 November 2003, with Sym-H $(\min )=-490 \mathrm{nT}$ (blue curve), the spectra for $\mathrm{H}^{+}$, $\mathrm{O}^{+}$and $\mathrm{He}^{+}$ions are hardest among all the selected geomagnetic storms showing the acceleration of the particles in the plasma sheet. This higher acceleration of $\mathrm{H}^{+}, \mathrm{O}^{+}$ and $\mathrm{He}^{+}$ions could be attributed to higher strength of southward IMF Bz (-55 nT) for longer duration (12 h). Thus, the geomagnetic storms having less hardening and hence less acceleration of the ions show lower magnitude of Sym-H decrease.

\section{Estimation of storm time energy density variations with intensity of the storm-}

We attempted to quantify the energy density and flux enhancements of $\mathrm{O}^{+}, \mathrm{H}^{+}$and $\mathrm{He}^{+}$ions. The obtained results are compared with earlier studies, and it is observed that the plasma sheet $\left\langle\varepsilon_{\mathrm{O}_{+}}\right\rangle$and $\left\langle\varepsilon_{\mathrm{He}+}\right\rangle$ are well in agreement with the results obtained by Kronberg et al. (2017) for $>40 \mathrm{keV}$ energies. The results are extended to bring a quantitative approach, which provides the comprehensive understanding of plasma sheet ions, the role of interplanetary parameters and intensity of the geomagnetic storms in enhancement of $\mathrm{O}^{+}, \mathrm{H}^{+}$ and $\mathrm{He}^{+}$ions.

Some studies have found that the energy density ratios for $\mathrm{O}^{+} / \mathrm{H}^{+}$and $\mathrm{He}^{+} / \mathrm{H}^{+}$strongly depend on the geomagnetic conditions (Ipavich et al. 1984; Nosé et al. 2001) by considering a few case studies. In this work, we examined the Kp dependence of $\left\langle\varepsilon_{\mathrm{O}+/} \varepsilon_{\mathrm{H}+}>\right.$ and $\left\langle\varepsilon_{\mathrm{He}+/} \varepsilon_{\mathrm{H}+}>\right.$ for all the storms from Geotail and RBSP observations (given in Table 2) separately shown in Fig. 10. It is known that the energy densities of $\mathrm{O}^{+}, \mathrm{H}^{+}$and $\mathrm{He}^{+}$ions shows considerable variation in $\left(X_{\mathrm{GSE}}, Y_{\mathrm{GSE}}\right)$ (Ohtani et al. 2011). Hence, for removing the effects from different regions and to reduce the dawn-dusk asymmetry, we normalize the energy densities and applied the correction factor (from Fig. 8(d) in Ohtani et al. 2011). It is observed that $<\varepsilon_{\mathrm{O}+/} \varepsilon_{\mathrm{H}+}>\mathrm{S}$ and $\left\langle\varepsilon_{\mathrm{He}+/} \varepsilon_{\mathrm{H}+}\right\rangle_{\mathrm{S}}$ depends on the average values of $\mathrm{Kp}$ index (i.e., $<\mathrm{Kp}>_{\mathrm{S}}$ ). From Geotail observations, the correlation coefficient for $\mathrm{O}^{+} / \mathrm{H}^{+}$was found to be 0.73 , while for $\mathrm{He}^{+} / \mathrm{H}^{+}$, it is 0.65 . This is consistent with the observations from RBSP spacecraft (CC for $<\varepsilon_{\mathrm{O}+/} \varepsilon_{\mathrm{H}+}>=0.86$ and $\mathrm{CC}$ for $\left\langle\varepsilon_{\mathrm{He}+/} \varepsilon_{\mathrm{H}+}>=0.60\right)$. The regression curve for $\left\langle\varepsilon_{\mathrm{O}+/} \varepsilon_{\mathrm{H}+}\right\rangle$ using Geotail observations is $Y=7.3 \times 10^{0.09^{*} \mathrm{Kp}}$ and using RBSP observations is $Y=0.04 \times 10^{(0.04 * \mathrm{Kp})}$. To determine the significance of our

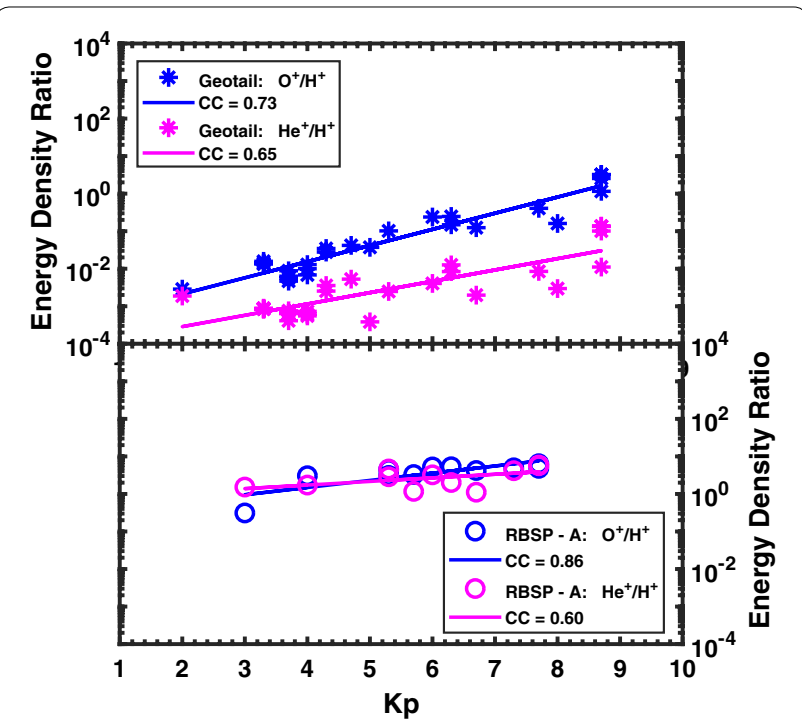

Fig. 10 Based on Geotail and RBSP-A observations, variation of energy density ratio for $\mathrm{O}^{+} / \mathrm{H}^{+}$and $\mathrm{He}^{+} / \mathrm{H}^{+}$with respect to $\mathrm{Kp}$ is shown. Blue and pink data points correspond to the energy density ratios of $\mathrm{O}^{+} / \mathrm{H}^{+}$and $\mathrm{He}^{+} / \mathrm{H}^{+}$, respectively. Black-colored regression line corresponds to each data set

results, we calculated the $P$-values that are based on null hypothesis. The $P$ value for $\mathrm{O}^{+} / \mathrm{H}^{+}$relation was found to be less than 0.0001 , and for $\mathrm{He}^{+} / \mathrm{H}^{+}$, it is less than 0.0022 . This shows that the calculated correlation coefficients are significant. Additionally, the Geotail observations of only four magnetic storms of 1998 having minimum Dst $(-50 \mathrm{nT})$ have shown a strong correlation of 0.88 for $\mathrm{O}^{+} /$ $\mathrm{H}^{+}$(Nosé et al. 2001).

To quantify our outcome with other studies, we have plotted Fig. 11 that gives the Geotail observations on the energy density change. These results complete the observations of all events of solar cycles 23 and 24 and thus one can estimate the energy densities by knowing the intensity of the storm. The extension of the observations made by Nosé et al. (2005), with our results is shown in Fig. $11 \mathrm{a}$, which is the summary plot showing the dependence of $\mathrm{O}^{+} / \mathrm{H}^{+}$energy density ratio with Sym-H or Dst. Here, we have added all the moderate and intense geomagnetic storms to evaluate and extend the previous studies made by Nosé et al. (2001, 2003, 2005) and the energy density ratio marked with red, blue and green corresponds to the studies from references. The black data points are the geomagnetic storms fitted to the plot from our studies. Figure 11b shows the energy density of four geomagnetic storms of 1998 (Nosé et al. 2001) (shown in blue) extended with our observations. The geomagnetic storms for which Sym-H or Dst falls above $-25 \mathrm{nT}$ are considered as the quiet interval. It is observed that the intensity of geomagnetic storm or ring current is 


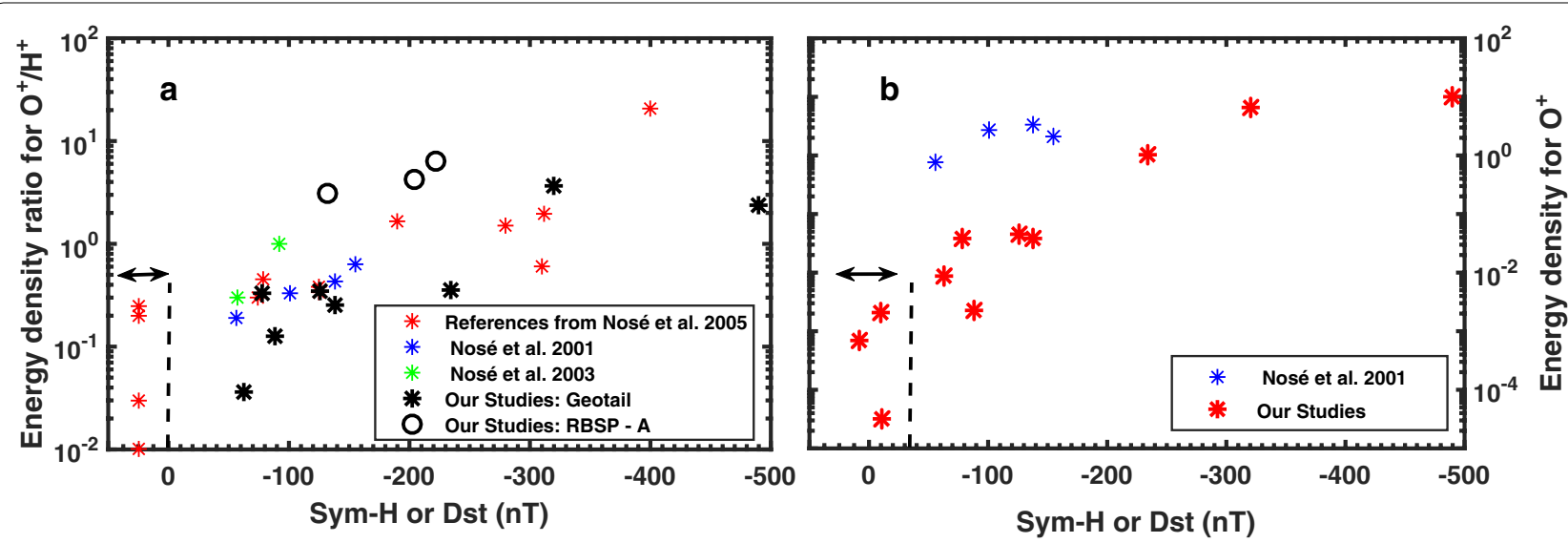

Fig. 11 Summary plot using Geotail observations (a) showing dependence of $\mathrm{O}^{+} / \mathrm{H}^{+}$energy density ratio on Sym- $\mathrm{H}$ or Dst in the ring current and the plasma sheet. Red, blue and green data points correspond to the energy density ratio reported from previous studies and references there in Nosé et al. $(2005,2001,2003)$, respectively. The data points represented in black are outcome from this study. Black vertical dashed line at 0 nT is the boundary for quiet interval. b The energy density variation of $\mathrm{O}^{+}$ions with respect to Sym-H or Dst. The blue data points correspond to the energy density values measured by Nosé et al. (2001) while red data set corresponds to the energy density values measured in this study. The quiet interval is considered above $-25 \mathrm{nT}$, shown by black vertical dashed line

dependent on $\mathrm{O}^{+} / \mathrm{H}^{+}$and $\mathrm{O}^{+}$ion composition change in the near-Earth plasma sheet. Hence, $\mathrm{O}^{+} / \mathrm{H}^{+}$ion composition changes in the near-Earth plasma sheet have been compared with those in the ring current. It is evident that $<\varepsilon_{\mathrm{O}+/ \mathrm{H}+}>$ shows more enhancement for RBSP observations than Geotail (Fig. 11). This is possibly due to the RBSP observations at lower L values (Fig. 8) than Geotail. Moreover, the ionospheric source increases closer to the Earth and there can also be additionally preferential acceleration of $\mathrm{O}^{+}$ions. This confirms previous findings (e.g., Kistler et al. 2016) and is very much consistent with the recent HOPE observations by Fernandes et al. (2017).

The energy-time spectrogram obtained using RBSP observations (Fig. 6) also confirms the flux enhancement at the higher energies giving acceleration of the convecting ions from the plasma sheet into the inner magnetosphere. Hence, observations from the two spacecrafts help in explaining the inward convection and acceleration of $\mathrm{O}^{+}$ions from the plasma sheet to the inner magnetosphere. The observations of 17 March 2015 show that the energy density (shown in Fig. 2) and flux (shown in Fig. 6a), measured simultaneously at two different locations, for all the three ion species increase with the onset of geomagnetic storm main phase. It clearly reflects the fresh plasma injection from the plasma sheet into the inner magnetosphere.

The two major routes through which the ionospheric $\mathrm{O}^{+}$ions can enter plasma sheet are: (1) the dayside cusp region that convects through the lobe, undergo reconnection and enters the nightside plasma sheet and (2) nightside aurora region (Lotko 2007; Yu and Ridley 2013). Speiser (1965) first addressed the acceleration mechanism of particles in the current sheet, from the magnetotail toward the inner magnetosphere. In the proximity of the current sheet, the spatial scale of magnetic field change is less than the particle gyro-radius. Hence, the first adiabatic invariant is not conserved. So the particles injected in the current sheet undergo energization by dawn-dusk convection electric field. The plausible mechanism for the acceleration of $\mathrm{O}^{+}$ions is the non-adiabatic local acceleration due to oscillating electric field associated with the magnetic fluctuations (Nosé et al. 2016). This discussion only deals with the $\mathrm{O}^{+}$ion dynamics; however, $\mathrm{H}^{+}$ions are also expected to behave similarly.

\section{Summary}

The complexity of ion composition variations in the near-Earth plasma sheet and inner magnetosphere during the main phase of the geomagnetic storms is investigated in this work by using two satellite-based observations. It is clear that these energy density variations are dependent on the intensity of the storm, but the extent of enhancement of the energy density ratio is quantified by considering some of the events of earlier studies which cover geomagnetic storms during solar maximum of solar cycle 23 and 24 . Additionally, we analyzed the possible role of the strength of southward IMF $\mathrm{Bz}$ and solar wind dynamic pressure. The major outcomes of the present study are: (1) Geotail and RBSP observations reveal that the energy densities of $\mathrm{H}^{+}, \mathrm{O}^{+}$and $\mathrm{He}^{+}$ions and the ratios $\mathrm{O}^{+} / \mathrm{H}^{+}$and $\mathrm{He}^{+} /$ $\mathrm{H}^{+}$in the near-Earth plasma sheet and the inner magnetosphere were nearly constant before the onset of the 
storm and increases with the geomagnetic activity. (2) During intense geomagnetic storms, $\mathrm{O}^{+}$is the dominating ion. (3) Plasma sheet ion composition depends on the strength of IMF $\mathrm{Bz}$, Psw and the time duration for which the IMF Bz remains southward. (4) The Kp index has a fairly good dependence on $\mathrm{O}^{+} / \mathrm{H}^{+}(\mathrm{CC}=0.74)$ and $\mathrm{He}^{+} / \mathrm{H}^{+}(\mathrm{CC}=0.58)$. (5) The energy density of $\mathrm{keV}$ range ionospheric ions is found to be higher in the near-Earth region $(L=2-4)$, which keeps on reducing as we move farther away from the Earth $(L>4)$. Thus, two satellite observations helped in finding evidence of the fact that the inner magnetospheric plasma is replaced with fresh plasma from the plasma sheet. Hence, the plasma sheet and inner magnetospheric ion composition are found to vary similarly as inferred in the previous studies and found to be consistent with the existing picture of the nightside magnetosphere.

\begin{abstract}
Abbreviations
EPIC: energetic particle and ion composition; ICS: ion composition system: STICS: suprathermal ion composition spectrometer; RBSP: Radiation Belt Storm Probe; ECT: energetic particle composition and thermal plasma suite; HOPE: helium, oxygen, proton and electron; AE: auroral electrojet; Kp: planetary K-index; MLT: magnetic local time.
\end{abstract}

\section{Authors' contributions}

MP has selected the data sets, performed statistical analysis and drafted the manuscript with help of BV. BV, MN interpreted data based on the results and manuscript, and SK helped to analyze figures. MN, ATYL and GR provided and helped to study the Geotail and RBSP data. All authors read and approved the final manuscript.

\section{Author details}

${ }^{1}$ Indian Institute of Geomagnetism, New Panvel, Navi Mumbai - 410218, India. ${ }^{2}$ Data Analysis Centre for Geomagnetism and Space Magnetism, Graduate School of Science, Kyoto University, Kyoto, Japan. ${ }^{3}$ Space and Atmospheric Sciences Group, Los Alamos National Laboratory, Los Alamos, NM, USA.

${ }^{4}$ Johns Hopkins University Applied Physics Laboratory, Laurel, MD, USA.

\section{Acknowledgements}

We are thankful to the Director, Indian Institute of Geomagnetism, for his interest and encouragement for carrying out this work. We gratefully acknowledge the use of online data of solar wind and interplanetary magnetic field (B) from NASA/GSFC's OMNI data set through OMNIWeb. Our sincere thanks to T. Nagai and Y. Saito for Geotail magnetic field and plasma data provided through DARTS at Institute of Space and Astronautical Science, JAXA, in Japan.

\section{Competing interests}

The authors declare that they have no competing interests.

\section{Availability of data and materials}

Dst index is obtained from World Data Centre for Geomagnetism, Kyoto (http://wdc.kugi.kyoto-u.ac.jp/index.html). The list of the month's quiet days is obtained from http://wdc.kugi.kyoto-u.ac.jp/qddays/index.html. Sym-H and interplanetary parameters like Psw and Bz are obtained from the CDAWeb data set available at https://cdaweb.sci.gsfc.nasa.gov/index.html and http:// www.srl.caltech.edu/ACE/ASC/. The Kp index is obtained from GFZ German Research Centre for Geosciences at ftp://ftp.gfz-potsdam.de/pub/home/obs/ kp-ap/wdc/. ECT-HOPE data are available at http://www.rbsp-ect.lanl.gov.

\section{Consent for publication}

Not applicable.
Ethics approval and consent to participate Not applicable.

Funding

Department of Science and Technology, India.

\section{Publisher's Note}

Springer Nature remains neutral with regard to jurisdictional claims in published maps and institutional affiliations.

Received: 13 February 2018 Accepted: 11 December 2018

Published online: 20 December 2018

\section{References}

Alex S, Pathan BM, Lakhina GS (2005) Response of the low latitude geomagnetic field to the major proton event of November 2001. Adv Space Res 36(12):2434-2439. https://doi.org/10.1016/j.asr.2004.01.026

André M (2015) Previously hidden low-energy ions: a better map of near-Earth space and the terrestrial mass balance. Phys Scr 90(12):128005. https:// doi.org/10.1088/0031-8949/90/12/128005

Chappell CR, Moore TE, Waite JH (1987) The ionosphere as a fully adequate source of plasma for the Earth's magnetosphere. J Geophys Res Space Phys 92(A6):5896-5910. https://doi.org/10.1029/JA092iA06p05896

Daglis IA (2006) Ring current dynamics. Space Sci Rev 124(1-4):183-202. https ://doi.org/10.1007/s11214-006-9104-z

Daglis IA, Kasotakis G, Sarris ET, Kamide Y, Livi S, Wilken B (1999) Variations of the ion composition during an intense magnetic storm and their consequences. Phys Chem Earth Part C 24(1):229-232. https://doi.org/10.1016/ S1464-1917(98)00033-6

Denton MH, Reeves GD, Thomsen MF, Henderson MG, Friedel RHW, Larsen B, Skoug RM, Funsten HO, Spence HE, Kletzing CA (2016) The complex nature of storm-time ion dynamics: transport and local acceleration. Geophys Res Lett 43:10059-10067. https://doi.org/10.1002/2016GL070878

Ebihara Y, Yamada M, Watanabe S, Ejiri M (2006) Fate of outflowing suprathermal oxygen ions that originate in the polar ionosphere. J Geophys Res Space Phys 111:A04219. https://doi.org/10.1029/2005JA011403

Ferradas CP, Zhang JC, Spence HE, Kistler LM, Larsen BA, Reeves G, Skoug R, Funsten $\mathrm{H}$ (2016) Ion nose spectral structures observed by the Van Allen Probes. J Geophys Res Space Phys 121:12,025-12,046. https://doi. org/10.1002/2016JA022942

Fernandes PA et al (2017) The plasma environment inside geostationary orbit: a Van Allen Probes HOPE survey. J Geophys Res Space Phys 122:92079227. https://doi.org/10.1002/2017JA024160

Funsten $\mathrm{HO}$ et al (2013) Helium, oxygen, proton, and electron (HOPE) mass spectrometer for the Radiation Belt Storm Probes mission. In: Fox N, Burch JL (eds) The Van Allen Probes mission. Springer, Boston. https://doi. org/10.1007/978-1-4899-7433-4_13

Gloeckler G, Wilken B, Stridemann W, Ipavich FM, Hovestadt D, Hamilton DC, Kremser $G$ (1985) First composition measurement of the bulk of the storm-time ring current (1 to $300 \mathrm{keV} / \mathrm{e}$ ) with AMPTE/CCE. Geophys Res Lett 12:325-328. https://doi.org/10.1029/GL012i005p00325

Gopalswamy N, Yashiro S, Michalek G, Xie H, Lepping RP, Howard RA (2005) Solar source of the largest geomagnetic storm of cycle 23. Geophys Res Lett. https://doi.org/10.1029/2004GL021639

Greenspan ME, Hamilton DC (2002) Relative contributions of $\mathrm{H}^{+}$and $\mathrm{O}^{+}$to the ring current energy near magnetic storm maximum. J Geophys Res Space Phys 107(A4):1043. https://doi.org/10.1029/2001 JA000155

Grigorenko EE, Malykhin AY, Kronberg EA, Malova KV, Daly PW (2015) Acceleration of ions to suprathermal energies by turbulence in the plasmoid-like magnetic structures. J Geophys Res Space Phys 120:6541-6558. https:// doi.org/10.1002/2015JA021314

Hamilton DC, Gloeckler G, Ipavich FM, Stüdemann W, Wilken B, Kremser G (1988) Ring current development during the great geomagnetic storm of February 1986. J Geophys Res Space Phys 93(A12):14343-14355

Ipavich FM, Galvin AB, Gloeckler G, Hovestadt D, Klecker B, Scholer M (1984) Energetic (> $100 \mathrm{keV}) \mathrm{O}^{+}$ions in the plasma sheet. Geophys Res Lett 11(5):504-507. https://doi.org/10.1029/GL011i005p00504 
lyemori T, Takeda M, Nose M, Odagi Y, Toh H (2010) Mid-latitude geomagnetic indices "ASY" and "SYM" for 2009 (Provisional). Data Analysis Center for Geomagnetism and Space Magnetism, Graduate School of Science, Kyoto University, Kyoto

Jordanova VK (2013) Sources, transport, and losses of energetic particles during geomagnetic storms, the inner magnetosphere: physics and modelling. In: Pulkkinen TI, Tsyganenko NA, Friedel RHW (eds) Monographs series, vol 155. AGU, Washington, DC, p 9. https://doi.org/10.1029/155gm 02

Jordanova VK, Thorne RM, Farrugia CJ, Dotan Y, Fennell JF, Thomsen MF, Reeves GD, McComas DJ (2001) Ring current dynamics during the 13-18 July 2000 storm period. Sol Phys 204(1):361-375. https://doi. org/10.1023/A:101424152

Keika K, Kistler LM, Brandt PC (2013) Energization of $\mathrm{O}^{+}$ions in the Earth's inner magnetosphere and the effects on ring current buildup: a review of previous observations and possible mechanisms. J Geophys Res Space Phys 118(7):4441-4464. https://doi.org/10.1002/jgra.50371

Kistler LM, Möbius E, Baumjohann W, Paschmann G, Hamilton DC (1992) Pressure changes in the plasma sheet during substorm injections. J Geophys Res Space Phys 97(A3):2973-2983. https://doi.org/10.1029/91JA02802

Kistler LM, Mouikis CG, Spence HE, Menz AM, Skoug RM, Funsten HO, Larsen BA, Mitchell DG, Gkioulidou M, Wygant JR, Lanzerotti LJ (2016) The source of $\mathrm{O}^{+}$in the storm time ring current. J Geophys Res Space Phys 121(6):5333-5349. https://doi.org/10.1002/2015JA022204

Kozyra JU, Liemohn MW, Clauer CR, Ridley AJ, Thomsen MF, Borovsky JE, Roeder JL, Jordanova VK, Gonzalez WD (2002) Multistep Dst development and ring current composition changes during the 4-6 June 1991 magnetic storm. J Geophys Res Space Phys. https://doi.org/10.1029/2001J A000023

Kronberg EA, Haaland SE, Daly PW, Grigorenko EE, Kistler LM, Fränz M, Dandouras I (2012) Oxygen and hydrogen ion abundance in the near-Earth magnetosphere: Statistical results on the response to the geomagnetic and solar wind activity conditions. J Geophys Res Space Phys. https://doi. org/10.1029/2012ja018071

Kronberg EA, Ashour-Abdalla M, Dandouras I, Delcourt DC, Grigorenko EE, Kistler LM, Kuzichev IV, Liao J, Maggiolo R, Malova HV, Orlova KG, Peroomian V, Shklyar DR, Shprits YY, Welling DT, Orlova KG (2014) Circulation of heavy ions and their dynamical effects in the magnetosphere: recent observations and models. Space Sci Rev 184(1-4):173-235. https://doi. org/10.1007/s11214-014-0104-0

Kronberg EA, Grigorenko EE, Haaland SE, Daly PW, Delcourt DC, Luo H, Kistler LM, Dandouras I (2015) Distribution of energetic oxygen and hydrogen in the near-Earth plasma sheet. J Geophys Res Space Phys 120:3415-3431. https://doi.org/10.1002/2014JA020882

Kronberg EA, Welling D, Kistler LM, Mouikis C, Daly PW, Grigorenko EE, Klecker B, Dandouras I (2017) Contribution of energetic and heavy ions to the plasma pressure: the 27 September to 3 October 2002 storm. J Geophys Res Space Phys 122:9427-9439. https://doi.org/10.1002/2017JA024215

Lotko W (2007) The magnetosphere-ionosphere system from the perspective of plasma circulation: a tutorial. J Atmos Sol Terr Phys 69(3):191-211. https ://doi.org/10.1016/j.jastp.2006.08.011

Mauk BH, Fox NJ, Kanekal SG, Kessel RL, Sibeck DG, Ukhorskiy A (2013) Science objectives and rationale for the radiation belt storm probes mission. Space Sci Rev 179(1-4):3-27. https://doi. org/10.1007/978-1-4899-7433-4_2

Möbius E, Scholer M, Klecker B, Hovestadt D, Gloeckler G (1987) Acceleration of ions of ionospheric origin in the plasma sheet during substorm activity. Magnetotail Phys 105:231-234
Nishida A (1994) The GEOTAIL mission. Geophys Res Lett 21:2871-2874

Nosé M, Ohtani S, Takahashi K, Lui ATY, McEntire RW, Williams DJ, Christon SP, Yumoto K (2001) Ion composition of the near-Earth plasma sheet in storm and quiet intervals: geotail/EPIC measurements. J Geophys Res Space Phys 106(A5):8391-8403. https://doi.org/10.1029/2000JA000376

Nosé M, McEntire RW, Christon SP (2003) Change of the plasma sheet ion composition during magnetic storm development observed by the Geotail spacecraft. J Geophys Res Space Phys 108(A5):1201-1210. https:// doi.org/10.1029/2002JA009660

Nosé M, Taguchi S, Hosokawa K, Christon SP, McEntire RW, Moore TE, Collier MR (2005) Overwhelming $\mathrm{O}^{+}$contribution to the plasma sheet energy density during the October 2003 superstorm: Geotail/EPIC and IMAGE/ LENA observations. J Geophys Res Space Phys 110(A9):A09S24. https:// doi.org/10.1029/2004JA010930

Nosé M, Keika K, Kletzing CA, Spence HE, Smith CW, MacDowall RJ, Reeves GD, Larsen BA, Mitchell DG (2016) Van Allen Probes observations of magnetic field dipolarization and its associated $\mathrm{O}^{+}$flux variations in the inner magnetosphere at $\mathrm{L}<6.6$. J Geophys Res Space Phys 121:7572-7589. https:// doi.org/10.1002/2016JA022549

Ohtani S, Nosé M, Christon SP, Lui ATY (2011) Energetic $\mathrm{O}^{+}$and $\mathrm{H}^{+}$ions in the plasma sheet: implications for the transport of ionospheric ions. J Geophys Res Space Phys 116:10211. https://doi.org/10.1029/2011JA016532

Ohtani S, Nosé M, Miyashita Y, Lui ATY (2015) Responses of different ion species to fast plasma flows and local dipolarization in the plasma sheet. J Geophys Res Space Phys 120:187-200. https://doi.org/10.1002/2014J A020517

Pulkkinen TI, Ganushkina NY, Baker DN, Turner NE, Fennell JF, Roeder J et al (2001) Ring current ion composition during solar minimum and rising solar activity: polar/CAMMICE/MICS results. J Geophys Res Space Phys 106(A9):19131-19147

Sarno-Smith LK, Liemohn MW, Katus RM, Skoug RM, Larsen BA, Thomsen MF, Wygant JR, Moldwin MB (2015) Postmidnight depletion of the high-energy tail of the quiet plasmasphere. J Geophys Res Space Phys 120:1646-1660. https://doi.org/10.1002/2014JA020682

Schlemm C II, Liu ATY, Gloeckler G, Gliem F (1994) Geotail energetic particles and ion composition instrument. J Geomagn Geoelectr 46(1):39-57

Speiser TW (1965) Particle trajectories in model current sheets, 1, analytical solutions. J Geophys Res Space Phys 70:4219-4226

Sugiura M, Kertz W, Price AT, Stone DJ (1964) Part I: hourly values of equatorial Dst for the IGY: Part. II. Ring current variations during the IGY. Pergamon Press, Oxford

Takahashi K, Zanetti LJ, Lopez RE, McEntire RW, Potemra TA, Yumoto K (1987) Disruption of the magnetotail current sheet observed by AMPTE/CCE. Geophys Res Lett 14(10):1019-1022. https://doi.org/10.1029/GL014i010p 01019

Yu Y, Ridley AJ (2013) Exploring the influence of ionospheric O + outflow on magnetospheric dynamics: dependence on the source location. J Geophys Res Space Phys 118:1711-1722. https://doi.org/10.1029/2012J A018411

Zesta E, Singer HJ, Lummerzheim D, Russell CT, Lyons LR, Brittnacher MJ (2013) The effect of the January 10, 1997, pressure pulse on the magnetosphere-ionosphere current system. Magnetos Curr Syst 118:217-226

Zhao H et al (2015) The evolution of ring current ion energy density and energy content during geomagnetic storms based on Van Allen Probes measurements. J Geophys Res Space Phys 120:7493-7511. https://doi. org/10.1002/2015JA021533 